\title{
Sex chromosome quadrivalents in oocytes of the African pygmy mouse Mus minutoides that harbors non-conventional sex chromosomes
}

\author{
Frédéric Baudat ${ }^{1}$ (I) $\cdot$ Bernard de Massy ${ }^{1} \cdot$ Frédéric Veyrunes $^{2}$
}

Received: 14 November 2018 / Revised: 7 March 2019 / Accepted: 12 March 2019

(C) Springer-Verlag GmbH Germany, part of Springer Nature 2019

\begin{abstract}
Eutherian mammals have an extremely conserved sex-determining system controlled by highly differentiated sex chromosomes. Females are $\mathrm{XX}$ and males $\mathrm{XY}$, and any deviation generally leads to infertility, mainly due to meiosis disruption. The African pygmy mouse (Mus minutoides) presents an atypical sex determination system with three sex chromosomes: the classical $\mathrm{X}$ and $\mathrm{Y}$ chromosomes and a feminizing $\mathrm{X}$ chromosome variant, called $\mathrm{X}^{*}$. Thus, three types of females coexist $\left(\mathrm{XX}, \mathrm{XX} *\right.$, and $\left.\mathrm{X}^{*} \mathrm{Y}\right)$ that all show normal fertility. Moreover, the three chromosomes ( $\mathrm{X}$ and $\mathrm{Y}$ on one side and $\mathrm{X}^{*}$ on the other side) are fused to different autosomes, which results in the inclusion of the sex chromosomes in a quadrivalent in $\mathrm{XX}^{*}$ and $\mathrm{X}^{*} \mathrm{Y}$ females at meiotic prophase. Here, we characterized the configurations adopted by these sex chromosome quadrivalents during meiotic prophase. The $\mathrm{XX}^{*}$ quadrivalent displayed a closed structure in which all homologous chromosome arms were fully synapsed and with sufficient crossovers to ensure the reductional segregation of all chromosomes at the first meiotic division. Conversely, the $\mathrm{X} * \mathrm{Y}$ quadrivalents adopted either a closed configuration with non-homologous synapsis of the $\mathrm{X}^{*}$ and $\mathrm{Y}$ chromosomes or an open chain configuration in which $\mathrm{X}^{*}$ and $\mathrm{Y}$ remained asynapsed and possibly transcriptionally silenced. Moreover, the number of crossovers was insufficient to ensure chromosome segregation in a significant fraction of nuclei. Together, these findings raise questions about the mechanisms allowing $\mathrm{X}^{*} \mathrm{Y}$ females to have a level of fertility as good as that of $\mathrm{XX}$ and $\mathrm{XX}^{*}$ females, if not higher.
\end{abstract}

Keywords African pygmy mouse $\cdot$ Sex chromosome quadrivalent $\cdot$ Non-homologous synapsis $\cdot$ MLH1 $\cdot$ Meiotic recombination $\cdot$ $\mathrm{XY}$ female

\section{Introduction}

Sexual reproduction relies on meiosis, the specialized division cycle where a single round of replication followed by two

This article is part of a Special Issue on Recent advances in meiosis from DNA replication to chromosome segregation "edited by Valérie Borde and Francesca Cole, co-edited by Paula Cohen and Scott Keeney."

Electronic supplementary material The online version of this article (https://doi.org/10.1007/s00412-019-00699-4) contains supplementary material, which is available to authorized users.

Frédéric Baudat

frederic.baudat@igh.cnrs.fr

Frédéric Veyrunes

frederic.veyrunes@umontpellier.fr

1 Institut de Génétique Humaine, Centre National de la Recherche Scientifique, Université de Montpellier, Montpellier, France

2 Institut des Sciences de l'Evolution, ISEM UMR 5554 (CNRS/Université Montpellier/IRD/EPHE), Montpellier, France divisions allows a diploid progenitor germ cell to give rise to haploid gametes. The intimate juxtaposition of homologous chromosomes within a specific proteinaceous structure (the synaptonemal complex) and meiotic recombination (reviewed in Hunter 2015) are two prominent features of this essential and highly choreographed phenomenon. Specifically, at the pachytene stage of meiotic prophase I, all pairs of homologs are synapsed along their entire length. In mammals, persistent asynapsed chromosomal regions generally trigger the elimination of meiocytes through not fully understood surveillance mechanisms, with the noteworthy exception of the specific regions of the $\mathrm{X}$ and $\mathrm{Y}$ chromosomes (i.e., non-pseudo-autosomal regions (non-PAR)) that remain asynapsed in males (reviewed in Burgoyne et al. 2009; Subramanian and Hochwagen 2014). The chromosomal regions that remain asynapsed undergo transcriptional silencing from the pachytene stage onward, while the genes situated in synapsed regions escape silencing, even when they are engaged in non-homologous synapsis that associates not 
homologous chromosomal regions (Baarends et al. 2005; Turner et al. 2005; Taketo and Naumova 2013; Cloutier et al. 2016). In Mus musculus females (i.e., the house mouse), the inappropriate transcriptional silencing of genes essential for gametogenesis in asynapsed chromosomal regions could be the main single cause of elimination of diplotene stage oocytes with synapsis defects (Cloutier et al. 2015). Conversely, the inappropriate expression of genes normally located on asynapsed, silenced regions (e.g., non-PAR of the $\mathrm{X}$ and $\mathrm{Y}$ chromosomes in male meiosis) might disrupt meiotic progression (Royo et al. 2010).

The role of homologous recombination in ensuring the accurate segregation of homologous chromosomes is better understood. Meiotic recombination initiates in early prophase with the programmed formation of DNA double-strand breaks that are repaired through interaction with the homologous chromosome (reviewed in Baudat et al. 2013; Hunter 2015). A subset of these events results in reciprocal exchanges, or crossovers. This will provide a physical link between homologs to ensure their proper alignment on the metaphase I plate, and then their accurate segregation. Therefore, at least one crossover per chromosome pair is necessary to ensure the segregation of every homo$\log$ and eventually the formation of viable, euploid gametes.

Eutherian mammals have an extremely conserved sex determining system controlled by highly differentiated sex chromosomes. Females are XX and males are XY, and any deviation generally leads to infertility/sterility, particularly due to meiosis disruption. This has been extensively studied in M. musculus through the generation of genetically manipulated mice with an uneven sex chromosome complement, such as $\mathrm{X} 0$ or sexreversed XY females (Eicher et al. 1982; Burgoyne and Baker 1985; Gubbay et al. 1992; Laval et al. 1995; Arboleda et al. 2014). A major cause of reduced fertility in $X 0$ females is the presence of a single $\mathrm{X}$ chromosome without pairing partner during meiotic prophase. This results in higher perinatal oocyte elimination, and consequently in a reduced oocyte pool and shorter reproductive lifespan (Burgoyne and Baker 1981, 1985). The high prevalence of asynapsed $X$ chromosomes (Speed 1986; Turner et al. 2005) could explain the oocyte elimination at diplotene that coincides with the increased perinatal oocyte loss in X0 females (reviewed in Burgoyne et al. 2009) due to transcriptional silencing of X-linked genes essential for gametogenesis (Cloutier et al. 2015). In sex-reversed XY mouse females, the $\mathrm{X}$ and $\mathrm{Y}$ chromosomes remain most often unpaired, and the $\mathrm{X}$ chromosome tends to behave like in $\mathrm{X} 0$ females (Mahadevaiah et al. 1993; Amleh et al. 2000; Baarends et al. 2005; Alton et al. 2008). Thus, the more severe fertility phenotype observed in most $\mathrm{XY}$ females compared with $\mathrm{X} 0$ females is due to the presence of the Y chromosome (Amleh et al. 2000; Alton et al. 2008; Vernet et al. 2014). The infertility of most M. musculus sex-reversed XY models has been attributed to the ectopic expression of Y-linked genes (especially Zfy2) in meiotic prophase oocytes. Consistent with this model, the fertility of sex-reversed $\mathrm{XY}$ females that carry a variant $\mathrm{Y}$ chromosome $\left(\mathrm{Y}^{\mathrm{d}}\right)$ in which $Z f y 2$ is transcriptionally repressed is comparable to that of X0 females (Vernet et al. 2014).

Although these sex chromosome modifications usually generate important meiotic impediments that greatly reduce fertility (or lead to sterility), a few mammalian lineages present atypical sex chromosomes that have evolved through millions of years of natural selection. These exceptions can be classified in three groups: (i) asynaptic and achiasmatic sex chromosomes, especially in voles and gerbils (the $\mathrm{X}$ and $\mathrm{Y}$ chromosomes do not have PAR and remain unpaired throughout meiosis) (e.g., de la Fuente et al. 2007; Borodin et al. 2012); (ii) multiple-sex-chromosome systems derived from fixed translocations between an autosome and the $\mathrm{X}$ or $\mathrm{Y}$ chromosome, giving rise to meiotic sex chromosome trivalents in males (multivalents involving more chromosomes are also possible following more complex rearrangements) (e.g., Fredga 1970; Dobigny et al. 2004; Veyrunes et al. 2014; Rahn et al. 2016; Vozdova et al. 2016); and (iii) atypical sex determination systems that differ from the ubiquitous $S r y$-dependent XX/XY system and that concern a handful of mammalian species only, where females are $\mathrm{X} 0$ or $\mathrm{XY}$ and/or males are $\mathrm{X} 0$ or $\mathrm{XX}$ (reviewed in Fredga 1994; Parma et al. 2016).

In this study, we investigated the meiotic behavior of the African pygmy mouse Mus minutoides, a very small rodent widespread throughout sub-Saharan Africa that alone among mammalian species exhibits the three previously described rare sex chromosome features. Specifically, the $\mathrm{X}$ and $\mathrm{Y}$ chromosomes are asynaptic (Britton-Davidian et al. 2012). The sex chromosomes are involved in several sex-autosome translocations that have given rise to several multiple-sex-chromosome systems in different populations (Veyrunes et al. 2004, 2007, 2010a, 2014). Finally, the most exciting feature is a novel atypical sex chromosome determination, with three sex chromosomes: $\mathrm{Y}, \mathrm{X}$, and a structurally variant of the $\mathrm{X}$, named $\mathrm{X}^{*}$, that is feminizing and thus produces sex-reversed and fully fertile females. Hence, three types of females with different sex chromosome complements are found $\left(\mathrm{XX}, \mathrm{XX}^{*}\right.$, and $\left.\mathrm{X}^{*} \mathrm{Y}\right)$, while all males are XY (Veyrunes et al. 2010b).

Here, we will focus on a peculiar population of M. minutoides from the Caledon Nature Reserve in South Africa, where a whole-arm reciprocal translocation (WART) complicated even more the system by producing multiple, complex, and never described meiotic sex chromosome configurations (Fig. 1a). Originally, the three sex chromosomes were all involved in the same sex-autosome translocation with pair 1 (Veyrunes et al. 2010b). This did not generate too many meiotic problems because the four sex genotypes (i.e., one male and the three female genotypes) produced only bivalents at meiosis. The problem of segregation was even partly solved by the formation of a neo-PAR (i.e., the sex-linked autosome 1) in males and in $\mathrm{X}^{*} \mathrm{Y}$ females during meiosis. However, this 
Fig. 1 Karyotype and meiotic sex chromosome conformation of $\mathrm{XX}, \mathrm{XX}^{*}$, and $\mathrm{X}^{*} \mathrm{Y}$

M. minutoides females. a Representative G-banded karyotypes of XX female (left), and in inserts the sex and neo-sex chromosomes of $\mathrm{XX}^{*}$ (middle), and $\mathrm{X}^{*} \mathrm{Y}$ (right) females. The numbers in parentheses designate the chromosome pairs involved in the Robertsonian $(\mathrm{Rb})$ fusions. $\mathbf{b}$ Schematic representation of the chromosomes involved in the sex-autosome $\mathrm{Rb}$ fusions and reciprocal whole-arm translocations in $\mathrm{XX}, \mathrm{XX}^{*}$, and $\mathrm{X}^{*} \mathrm{Y}$ females. $\mathbf{c}-\mathbf{h}$ Chromosome spreads of pachytene stage oocytes stained with antibodies against centromere proteins (CEN, CREST serum, light blue), meiotic chromosome axis (SYCP3, red), and synapsis markers (SYCP1, green).

Enlarged views from the nuclei in c-e to show two representative chromosomes in one XX oocyte (f) and the sex chromosomecontaining quadrivalent in one $\mathrm{XX}^{*}$ and one $\mathrm{X} * \mathrm{Y}$ oocyte $(\mathbf{g}, \mathbf{h})$. Drawings are shown below.

Recognizable chromosome arms are indicated by colored arrowheads, with the same color code as in $\mathbf{b}$. Scale bars $=10 \mu \mathrm{m}$ a
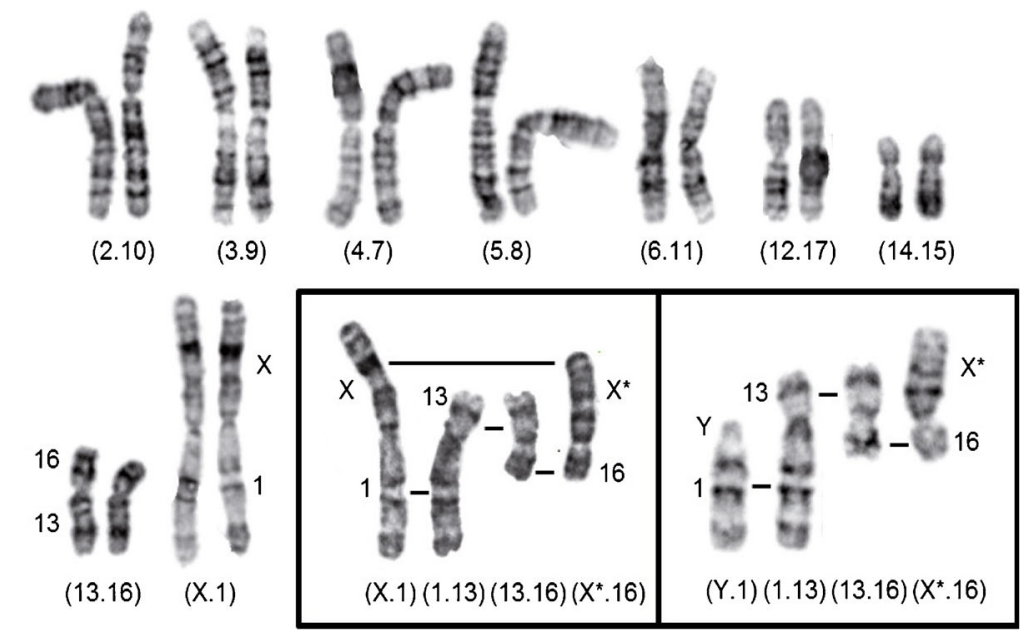

b

$X X$ female

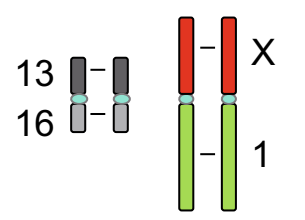

$\mathrm{XX}$
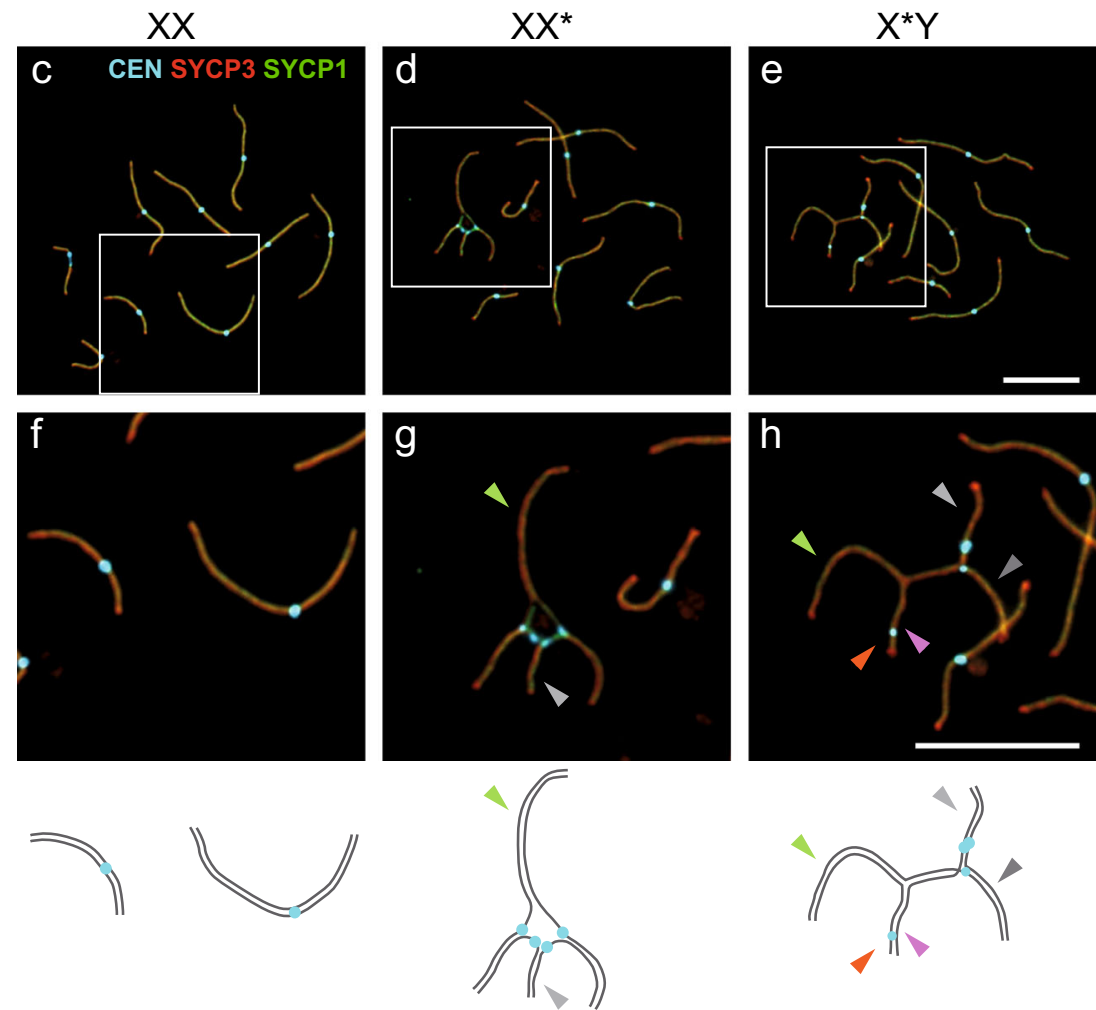
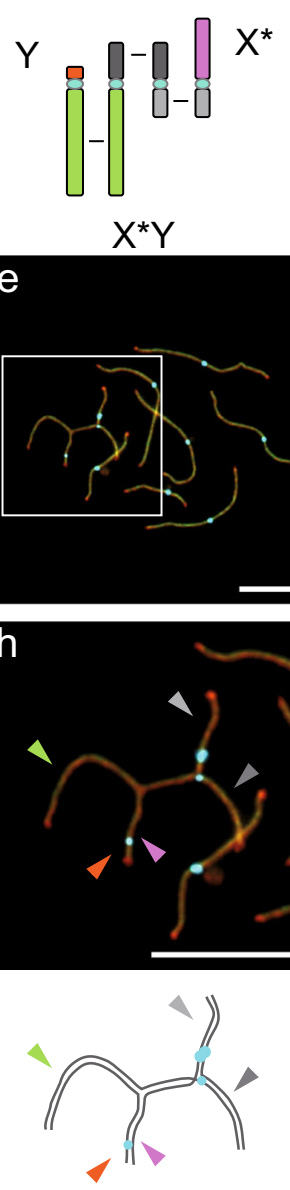

population is characterized by a further chromosomal rearrangement, a WART between the sex-autosome Robertsonian $(\mathrm{Rb})$ translocation $\mathrm{Rb}\left(\mathrm{X}^{*} .1\right)$ and the autosomal pair $\mathrm{Rb}(13.16)$ that gave rise to the new chromosome variants $\mathrm{Rb}\left(\mathrm{X}^{*} .16\right)$ and $\mathrm{Rb}$ (1.13) (Veyrunes et al. 2007; Veyrunes and Perez, 2018). Their presence did not affect males and XX females that still produce $(\mathrm{X} .1)(\mathrm{Y} .1)$ and $(\mathrm{X} .1)(\mathrm{X} .1)$ meiotic sex chromosome bivalents, respectively. Conversely, in $\mathrm{XX}^{*}$ and $\mathrm{X} * \mathrm{Y}$ females, both karyotypes are now composed of four heterozygous chromosomes with monobrachial homologies that must pair at meiosis and are expected to produce complex meiotic multivalents: a closed ring of four chromosomes (X.1)(1.13)(13.16)(16.X*) 
in $X^{*}$ females and an open chain of four (Y.1)(1.13)(13.16)(16.X*) chromosomes in $X^{*} Y$ females (see Fig. 1 for a description of the sex chromosomes and the expected meiotic configurations for each sex genotype). These kinds of meiotic configurations are expected to severely disrupt meiosis (Gruetzner et al. 2006). Additionally, in mammals, multivalents involving the sex chromosomes have been previously identified only in males (e.g., Rens et al. 2004; Gruetzner et al. 2006; Vozdova et al. 2016).

Hence, $M$. minutoides $\mathrm{X}^{*} \mathrm{Y}$ oocytes, and $\mathrm{XX}^{*}$ oocytes to a lesser extent, possess several features that challenge the meiotic machinery: (i) the presence of a $\mathrm{Y}$ chromosome in $\mathrm{X}^{*} \mathrm{Y}$ females; (ii) the sex chromosomes are either heterologous $\left(\mathrm{X}^{*} \mathrm{Y}\right)$ or have reduced homology $\left(\mathrm{XX}^{*}\right)$, instead of being fully homologous like in conventional XX females; and (iii) because of the complex chromosome rearrangements, sex chromosomes are expected to be part of quadrivalents. These features pose a threat to the pairing and synapsis of these chromosomes, to the appropriate control of the expression of X-linked and Y-linked genes, and to the generation of the minimum number of chiasmata (the cytological manifestation of crossovers) required for the segregation of all chromosomes. Here, we analyzed the meiotic behavior of the chromosomes of $M$. minutoides $\mathrm{XX}, \mathrm{XX}^{*}$, and $\mathrm{X}^{*} \mathrm{Y}$ females, and particularly the formation of synapsis and of crossovers on chromosome arms within the quadrivalents in $\mathrm{XX}^{*}$ and $\mathrm{X}^{*} \mathrm{Y}$ females. Then, we discussed how the meiotic behavior of quadrivalents may support the high level of fertility of XX* and $\mathrm{X}^{*} \mathrm{Y}$ females in $M$. minutoides.

\section{Materials and methods}

\section{Animals}

The karyotype of $M$. minutoides was published previously (Veyrunes et al. 2004). In our colony, their karyotype includes 18 bi-armed chromosomes, all resulting from $\mathrm{Rb}$ fusion events. Even the sex chromosomes are fused, but with different autosomes: Rb(Y.1), Rb(X.1), and $\mathrm{Rb}\left(\mathrm{X}^{*} .16\right)$ (Veyrunes et al. 2007). Mice were bred in our own laboratory colony (CECEMA facilities of Montpellier University) established from wild-caught animals (for further details, see Saunders et al. 2014). Two $\mathrm{XX}$, four $\mathrm{XX}^{*}$, and three $\mathrm{X}^{*} \mathrm{Y}$ fetuses (estimated between 15 and 17 days post coitum, dpc) of pregnant $\mathrm{XX}^{*}$ females (that give birth to $\mathrm{XX}, \mathrm{XX}^{*}$, and $\mathrm{X}^{*} \mathrm{Y}$ daughters, and $\mathrm{XY}$ sons) were collected. XX fetuses \#1 and $2, \mathrm{XX}^{*} \# 2-4$, and $\mathrm{X}^{*} \mathrm{Y} \# 3$ were all littermates, as were also $X^{*} \# 1$ and $X^{*} Y \# 1$ (Figs. S1 and S4). Mice were housed according to international standard conditions, and all animal experiments were performed in accordance with the European guidelines.

\section{Oocyte chromosome spreads and immunofluorescence}

Oocyte chromosome spreads from 15 to 17 -dpc female embryos were prepared using the dry-down method (Peters et al. 1997). Spreads were incubated at room temperature overnight with the following primary antibodies and dilutions: guinea pig antiSYCP3 polyclonal, 1:1000 (Grey et al. 2009); rabbit antiSYCP1polyclonal (Abcam, ab15090), 1:400; human CREST serum (Europa Bioproducts, FZ90C-CS1058), 1:500; mouse anti- $\gamma \mathrm{H} 2 \mathrm{AX}$ monoclonal (Millipore, 05-636), 1:10,000; mouse anti-MLH1 monoclonal (BD Pharmingen, 551091), 1:50; rabbit anti-DMC1 polyclonal (Santa Cruz, sc-22768, discontinued), 1:200; and rabbit anti-BRCA1 polyclonal (gift from Satoshi Namekawa; Ichijima et al. 2011), 1:750. Signals were visualized by incubation with goat anti-guinea pig IgG Alexa Fluor 488 (Molecular Probes, A-11073), goat anti-human IgG Alexa Fluor 568 (Molecular Probes, A-21090), donkey anti-mouse IgG Alexa Flour 647 (Molecular Probes, A-31571), goat anti-rabbit IgG Alexa Fluor 405 (Molecular Probes, A-31556), goat antirabbit IgG Alexa Fluor 488 (Molecular Probes, A-21206), or donkey anti-guinea pig IgG Cy5 (Jackson ImmunoResearch, 706-175-148) secondary antibodies at $37^{\circ} \mathrm{C}$ for $90 \mathrm{~min}$. After DAPI staining when required, slides were mounted using ProLong Gold Antifade (Thermo Fisher Scientific). Digital images were captured with a complementary metal-oxide-semiconductor (CMOS) camera (ORCA-Flash4.0 LT, Hamamatsu) attached to a Zeiss Axio Imager 2 microscope (Zeiss). After data acquisition with the ZEN imaging software (Zeiss), images were processed with OMERO (OME).

\section{Staging of pachytene nuclei}

We categorized pachytene stage nuclei in four classes (P1 to P4), according to the level of synapsis of the quadrivalent and the presence of strong $\gamma \mathrm{H} 2 \mathrm{AX}$ (the phosphorylated form of $\mathrm{H} 2 \mathrm{AX}$ ) signal covering part of its chromatin, as a marker of meiotic silencing of unsynapsed chromosomes (Fig. 2c). We

Fig. 2 Synapsis in $\mathrm{XX}, \mathrm{XX}^{*}$, and $\mathrm{X}^{*} \mathrm{Y}$ females. a Distribution of oocytes from $\mathrm{XX}, \mathrm{XX}^{*}$, and $\mathrm{X}^{*} \mathrm{Y}$ females in the different stages of prophase $\mathrm{I}$. Oocyte numbers: XX, $n=140 ; \mathrm{XX}^{*}, n=432 ; \mathrm{X}^{*} \mathrm{Y}, n=372$. b Distribution of pachytene oocytes from $\mathrm{XX}, \mathrm{XX}^{*}$, and $\mathrm{X}^{*} \mathrm{Y}$ females in the classes P1, P2, P3, and P4. In $X^{*}$ and $X^{*} Y, P 1$ and P2-P4 nuclei represent an open chain and a closed configuration of the quadrivalent, respectively. Oocyte numbers: $\mathrm{XX}, n=98 ; \mathrm{XX}^{*}, n=378 ; \mathrm{X}^{*} \mathrm{Y}, n=334$. c Representative images of selected chromosomes (XX) or the sex chromosome-containing quadrivalent $\left(\mathrm{XX}^{*}, \mathrm{X}^{*} \mathrm{Y}\right)$ in pachytene oocytes stained with antibodies against centromere proteins (CEN, CREST serum, light blue), meiotic chromosome axis (SYCP3, red) and synapsis (SYCP1, green) markers, and $\gamma \mathrm{H} 2 \mathrm{AX}$ (purple). Inset, schematic representation of the selected chromosomes with same color code as in Fig. 1. P1, 1-2 fully asynapsed chromosome arms; $\mathrm{P} 2$, one partially asynapsed arm; P3, full synapsis with strong extended $\gamma \mathrm{H} 2 \mathrm{AX}$ signal on 1-2 arms; P4, full synapsis with no strong $\gamma \mathrm{H} 2 \mathrm{AX}$ signal. Scale bar $=10 \mu \mathrm{m}$ 
assigned nuclei to the pachytene stage if the seven pairs of autosomes were fully synapsed. Then, we classified nuclei with a partially unsynapsed quadrivalent as P1 (one or two entirely unsynapsed arms) or P2 (presence of partially unsynapsed arms), and nuclei with all chromosome arms fully synapsed as $\mathrm{P} 3$ and $\mathrm{P} 4$, based on the presence (P3) or absence a

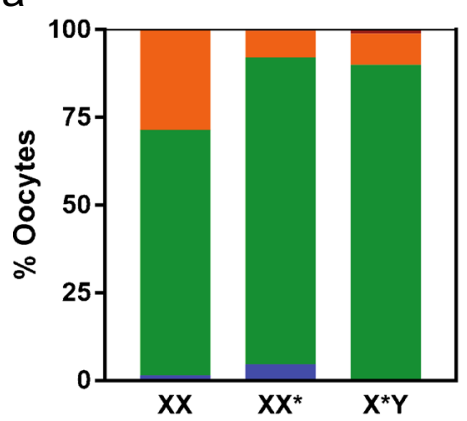

C

P1

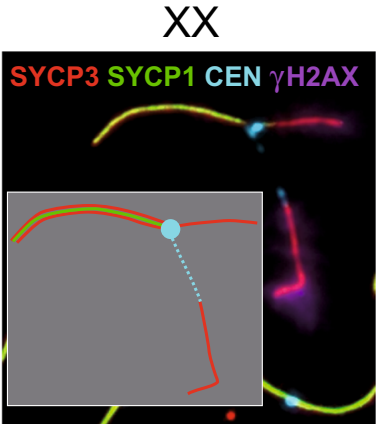

P2

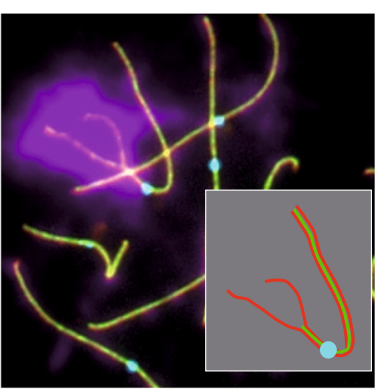

P3
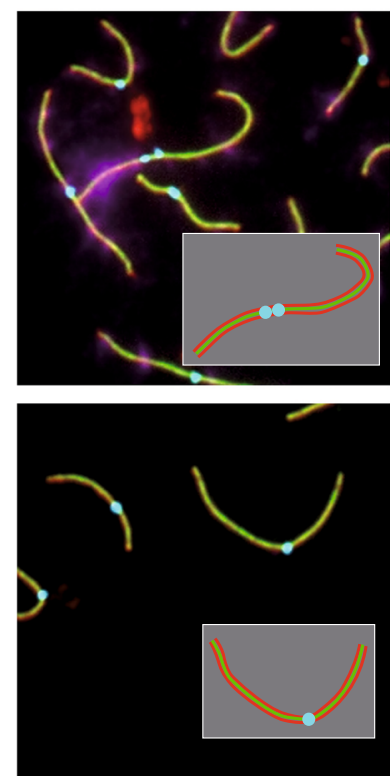

b
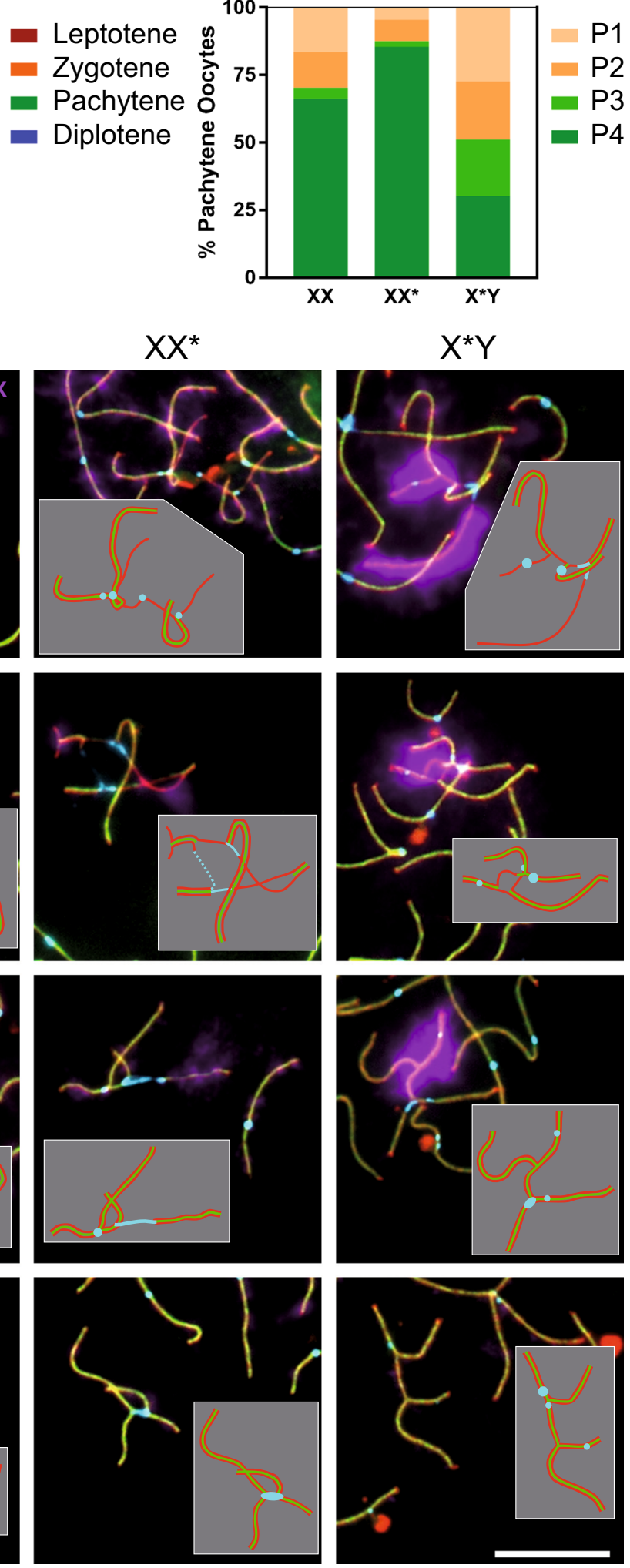
(P4) of strong $\gamma \mathrm{H} 2 \mathrm{AX}$ signal encompassing part of the chromatin surrounding the quadrivalent. For comparison, we assigned nuclei from XX females, in which the sex chromosomes remained unidentified, to the pachytene stage if seven or more bivalents were fully synapsed, and the others at least partially synapsed. Then, we classified nuclei with one or two partially unsynapsed bivalents as P1 (one or two entirely unsynapsed arms) or P2 (partially unsynapsed arms), and nuclei with nine fully synapsed bivalents as $\mathrm{P} 3$ or P4, depending on the presence (P3) or absence (P4) of strong $\gamma \mathrm{H} 2 \mathrm{AX}$ signal on one or two bivalents.

\section{Results}

\section{Formation of sex chromosome quadrivalents in $X^{*}$ * and $X * Y$ females}

The karyotype of $M$. minutoides individuals in our colony is typically composed of 18 bi-armed chromosomes $(2 n=18)$ as the result of $\mathrm{Rb}$ fusions of all chromosomes, including the sex chromosomes. The $\mathrm{X}$ and $\mathrm{Y}$ chromosomes are fused with chromosome $1(\mathrm{Rb}(\mathrm{X} .1)$ and $\mathrm{Rb}(\mathrm{Y} .1))$, and the karyotype of $\mathrm{XY}$ males and $\mathrm{XX}$ females comprises also the $\mathrm{Rb}(13.16)$ fusion at the homozygous state. The feminizing $\mathrm{X}^{*}$ chromosome is involved in a WART resulting into two new heterozygous chromosome variants, $\mathrm{Rb}(1.13)$ and $\mathrm{Rb}\left(\mathrm{X}^{*} .16\right)$. Thus, $\mathrm{XX}$ females possess a conventional karyotype made of nine pairs of homologous chromosomes, including $\mathrm{Rb}(13.16)$ and $\mathrm{Rb}(\mathrm{X} .1)$. On the other hand, $\mathrm{XX}^{*}$ females have seven pairs of classical homologous chromosome pairs, as well as four unique chromosomes: $\mathrm{Rb}(\mathrm{X} .1), \mathrm{Rb}(1.13), \mathrm{Rb}(13.16)$, and $\mathrm{Rb}\left(\mathrm{X}^{*} .16\right)$ translocations. In $X^{*} Y$ females, $\mathrm{Rb}(\mathrm{X} .1)$ is replaced by $\mathrm{Rb}(\mathrm{Y} .1)$ (Fig. 1a, b).

To characterize the configuration adopted during meiotic prophase by the four unique chromosomes in $\mathrm{XX}^{*}$ and $\mathrm{X}^{*} \mathrm{Y}$ females, we examined the formation of the synaptonemal complex in spread oocyte nuclei from 15 to 17-dpc fetuses using antibodies against SYCP3 and SYCP1 that are components of the axial and central element of the synaptonemal complex, respectively. In pachytene stage nuclei from XX females, we detected nine pairs of fully synapsed, metacentric bivalents, resulting from full synapsis of all homologous chromosome pairs. We could not distinguish the pair of sex chromosomes ( $\mathrm{Rb}(\mathrm{X} .1)$ ) from the autosomes (Fig. 1c, f). In pachytene nuclei from $\mathrm{XX}^{*}$ and $\mathrm{X}^{*} \mathrm{Y}$ females, we observed seven pairs of morphologically normal bivalents, corresponding to the expected seven pairs of autosomes. The remaining four chromosomes were encompassed in a single structure (Fig. 1d, $\mathrm{e}, \mathrm{g}, \mathrm{h}$ ). The quadrivalent was fully synapsed in many but not all nuclei, because a fraction of axes remained unsynapsed in many pachytene nuclei, particularly in $\mathrm{X} * \mathrm{Y}$ females.
The presence of a quadrivalent containing the sex chromosomes did not slow down the progression through meiotic prophase, as shown by the unaltered proportion of nuclei at various stages (Fig. 2a and Fig. S1a). The higher proportion of early stage (zygotene) nuclei that is observed in XX mice might result from individual variation rather than from the genotype (Fig. S1a). Of note, a similar proportion of earlier stage (leptotene and zygotene) nuclei was observed in $\mathrm{XX}^{*}$ and $\mathrm{X} * \mathrm{Y}$ females (7.9\% and $9.9 \%$, respectively; $p=0.3$, Fisher's exact test). In order to further characterize the synaptic behavior of the quadrivalent, we categorized pachytene nuclei in four classes (P1 to P4; Fig. 2b), according to the extent of synapsis of the quadrivalent and the level of $\gamma \mathrm{H} 2 \mathrm{AX}$ signal on the chromatin of the quadrivalent ("Materials and methods" section and Fig. 2c). In XX females, all chromosomes were fully synapsed in $70 \%$ of the nuclei assigned to the pachytene stage ( $\mathrm{P} 3$ and P4; Fig. 2b). This is most likely an underestimate, because late zygotene nuclei with one or two not fully synapsed autosome pairs were classified as P1 or P2 pachytene nuclei, according to our criteria. Consistent with this possibility, the XX female number 2, with a higher proportion of zygotene nuclei, also had a higher proportion of $\mathrm{P} 1$ and P2 nuclei (Fig. S1a, b).

In $\mathrm{XX}^{*}$ females, the quadrivalent adopted a closed configuration in which the four homologous arm pairs usually reached full synapsis (88\% were classified as $\mathrm{P} 3$ or P4; Fig. $2 b)$. The low proportion of $X^{*}$ nuclei in which the quadrivalent remained only partially synapsed (P1 and P2, 12\%), despite full synapsis of autosomes, suggested that neither the formation of a quadrivalent nor the partial heterology between $\mathrm{X}$ and $\mathrm{X}^{*}$ chromosomes inhibited the efficient formation of the synaptonemal complex.

In $X^{*} Y$ females, pachytene nuclei were equally distributed between a closed configuration with full synapsis (P3 and $\mathrm{P} 4,51 \%$ ), and a configuration with incomplete synapsis of the quadrivalent giving rise to either an open or a closed chain (P1 and P2, 49\%; Fig. 2b). Besides the lower fraction of full synapsis, $41 \%$ of $\mathrm{X}^{*} \mathrm{Y}$ nuclei with full synapsis showed strong $\gamma \mathrm{H} 2 \mathrm{AX}$ signal that covered part of the quadrivalent chromatin (P3). This proportion was negligible among $\mathrm{XX}$ and $\mathrm{XX} *$ nuclei $(6 \%$ and $2 \%$, respectively; Fig. 2b). This might result from the presence of residual unsynapsed regions that are too short to be detected cytologically, or from the persistence of some $\gamma \mathrm{H} 2 \mathrm{AX}$ signal on regions where synapsis was delayed. In all cases, this is an additional evidence for the synapsis delay or defect in $\mathrm{X} * \mathrm{Y}$ nuclei, and indicates that the presence of the $\mathrm{Rb}(\mathrm{Y} .1)$ chromosome instead of the $\mathrm{Rb}(\mathrm{X} .1)$ chromosome strongly affects the synapsis efficiency of the quadrivalent. The Y chromosome, which was easily identified due to its short length, was involved in almost 
every case of incomplete synapsis. This propensity to reduce synapsis efficiency might be an intrinsic property of the $\mathrm{Y}$ chromosome, or a consequence of the extensive heterology between the $\mathrm{X}^{*}$ and $\mathrm{Y}$ chromosomes.

The quadrivalent in $\mathrm{XX}^{*}$ comprises three pairs of autosomal arms that are expected to be fully homologous $(1,13$, and 16), and one pair of sex chromosome arms with reduced homology $\left(\mathrm{X} / \mathrm{X}^{*}\right)$. The $\mathrm{X}^{*}$ chromosome differs from the canonical $\mathrm{X}$ chromosome by the presence of extensive rearrangements including deletions and inversions (Veyrunes et al. 2007, 2010b). To assess the consequences of this reduced homology on synapsis, we examined the position of the centromeres on fully synapsed quadrivalents. If all three autosomal arms and the $\mathrm{X} / \mathrm{X}^{*}$ synapse in a homologous manner, the quadrivalent should adopt an $\mathrm{X}$-shape with all centromeres grouped together at the intersection of the arms (Fig. 3a). This X-shaped configuration was adopted by $45 \%$ of P3/P4 XX* nuclei (Fig. 3g), whereas the other nuclei displayed an $\mathrm{H}$-shaped configuration with more than one cluster of centromeres. We detected two centromere signals in $43 \%$ of nuclei (most often two centromeres clustered together at or near each arm intersection; Fig. 3b), three centromere signals in $11 \%$ (Fig. 3c), and four separated centromeres in $1 \%$ of nuclei. The separation of centromeres indicates that part of the autosomal arms undergoes nonhomologous synapsis. FISH would be required to precisely identify the chromosome arms. Here, we used the length differences (chromosome 1 is the longest and chromosome 16 the shortest) and the assumption that the $\mathrm{X} / \mathrm{X}^{*}$ arm is generally the last to synapse in late zygotene and in $\mathrm{P} 1 / \mathrm{P} 2$ nuclei to infer that the proximal regions of the $\mathrm{X}$ chromosome (from $\mathrm{Rb}(\mathrm{X} .1)$ ) and of chromosome 13 (from $\mathrm{Rb}(13.16)$ ) might often be involved in non-homologous synapsis (Fig. 3b, c).

In $\mathrm{X} * \mathrm{Y}$ females, the sex chromosome arms are heterologous and the $\mathrm{Y}$ chromosome is considerably shorter than the $\mathrm{X}^{*}$ chromosome. Strikingly, the four centromeres never clustered together in pachytene nuclei from $\mathrm{X} * \mathrm{Y}$ females (Fig. 3g). Instead, the centromere of $\mathrm{Rb}(\mathrm{Y} .1)$ close to the end of the $\mathrm{Y}$ arm was always apart from the three other centromeres. The other centromeres clustered together at one junction in $23 \%$ of nuclei (Fig. 3d), whereas we observed three centromere spots in $69 \%$ of nuclei. The archetypical configuration is displayed in Fig. 3e, with the centromere of $\mathrm{Rb}(\mathrm{Y} .1)$ close to the end of one arm (which allows its identification), the centromeres of $\mathrm{Rb}(13.16)$ and $\mathrm{Rb}\left(\mathrm{X}^{*} .16\right)$ together, and the centromere of $\mathrm{Rb}(1.13)$ at a variable position between them. Finally, the four centromeres were separated in $9 \%$ of nuclei (Fig. 3f). In $X * Y$ females, non-homologous synapsis involved the proximal regions of the chromosomes 1 and $\mathrm{X}^{*}$ in virtually every pachytene nucleus, and less frequently a proximal region of chromosome 13 and/or chromosome 16.

\section{Meiotic silencing of asynapsed chromosome axes}

The chromosomal regions that remain unsynapsed at the onset of pachytene are transcriptionally inactivated by a mechanism that is called meiotic silencing of unsynapsed chromosomes, and that involves accumulation of BRCA1 on the unsynapsed chromosome axes and the phosphorylation of $\mathrm{H} 2 \mathrm{AX}$ on the surrounding chromatin (Turner et al. 2004, 2005; Baarends et al. 2005; Royo et al. 2013). At leptonema, BRCA1 forms foci on chromosome axes that persist during zygonema on unsynapsed axes and disappear progressively from synapsed regions (Fig. S2). From pachytene stage onward, BRCA1 appears as a continuous intense signal restricted to the unsynapsed regions of the $\mathrm{X}$ and $\mathrm{Y}$ chromosomes in spermatocytes, and more generally to persisting unsynapsed portions of axes in spermatocytes and oocytes (Turner et al. 2004, 2005). This last BRCA1 signal is associated with bright $\gamma \mathrm{H} 2 \mathrm{AX}$ signal in the chromatin surrounding these unsynapsed axis portions.

Analysis of BRCA1 and $\gamma \mathrm{H} 2 \mathrm{AX}$ localization in spread nuclei from $\mathrm{XX}^{*}$ females (Fig. 4a, b) and $\mathrm{X}^{*} \mathrm{Y}$ females (Fig. $4 c-f)$ showed that in zygotene nuclei, BRCA1 foci along axes and $\gamma \mathrm{H} 2 \mathrm{AX}$ staining on the chromatin were present following the formation of DNA double-strand breaks (Fig. 4c). In late zygonema and in pachynema, both were restricted mostly to portions of unsynapsed axes, where the strong BRCA1 and $\gamma \mathrm{H} 2 \mathrm{AX}$ signals were correlated (Fig. 4a, d). We observed the same pattern of staining, although usually fainter, also in some nuclei on limited portions of synapsed regions (Fig. 4e). This might correspond to the remnants of stronger staining that marks regions of recent synapsis. The BRCA1 signal was essentially absent in pachytene nuclei without strong $\gamma \mathrm{H} 2 \mathrm{AX}$ signal (P4 nuclei; Fig. 4b, f). Altogether, these observations suggest that the mechanism of meiotic silencing of unsynapsed chromosomes is functional and active in pachytene oocytes from $M$. minutoides $\mathrm{XX}^{*}$ and $\mathrm{X}^{*} \mathrm{Y}$ females.

\section{Formation of crossovers on bivalents and quadrivalents}

The strand exchange proteins RAD51 and DMC1 colocalize and form chromosome-associated foci that allow visualizing unrepaired DSBs (Tarsounas et al. 1999). In M. musculus oocytes, DMC1 foci appear first in leptotene stage, reach a maximum during the zygotene stage, and vanish progressively from synapsed axes during late zygotene and early pachytene stages (Kolas et al. 2005a). Due to the lack of a homologous partner, RAD51 and DMC1 foci are retained on chromosome axes that remain asynapsed (such as the sex chromosomes in XY males) until mid-late pachynema (Moens et al. 1997; Tarsounas et al. 1999; Kauppi et al. 2013). In order to assess the formation and repair of DSB on the extensive regions of asynapsis or non-homologous synapsis on $\mathrm{X}^{*} \mathrm{Y}$ quadrivalent, we immunostained spread oocytes from one $\mathrm{X} * \mathrm{Y}$ female for 

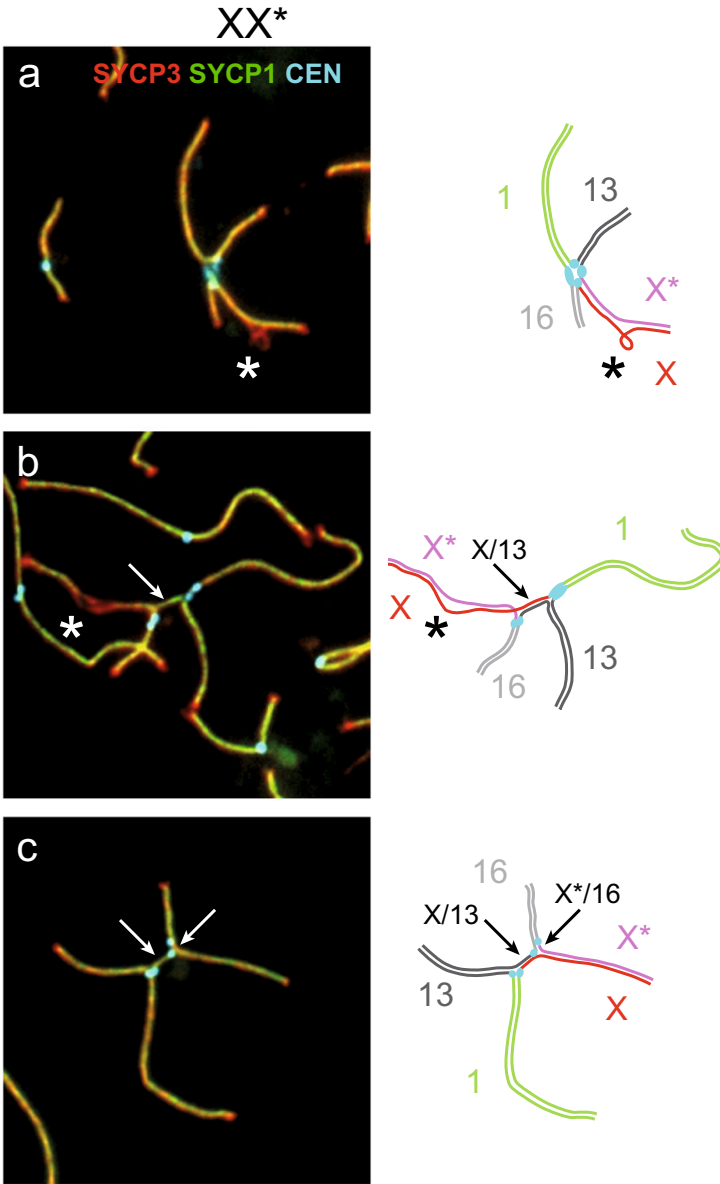

g

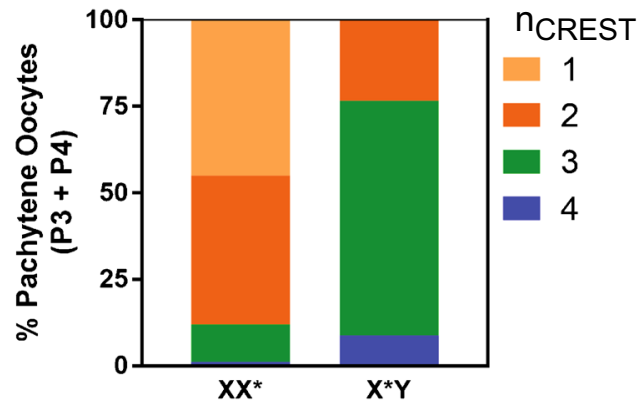

Fig. 3 Non-homologous synapsis in sex-autosome quadrivalents in $\mathrm{XX}^{*}$ and $\mathrm{X}^{*} \mathrm{Y}$ females. a-f Sex chromosome-containing quadrivalents from P2 $(\mathbf{a}, \mathbf{b})$ and P4 (c-f) pachytene oocytes of $X^{*}(\mathbf{a}-\mathbf{c})$ and $X^{*} \mathrm{Y}(\mathbf{d}-\mathbf{f})$ females stained with antibodies against centromere proteins (CEN, CREST serum, light blue), and meiotic chromosome axis (SYCP3, red) and synapsis (SYCP1, green) markers. Representative nuclei with 1 (a), 2 $(\mathbf{b}, \mathbf{d}), 3(\mathbf{c}, \mathbf{e})$, or 4 (f) centromere signals are shown. In the schematic

DMC1 (Fig. S3). DMC1 foci were numerous and spread over all chromosome axes in zygotene nuclei. In pachynema, the percent of nuclei with DMC1 spread over all chromosomes was decreasing from $34 \%$ in P1 nuclei (Fig. S3a) to $16 \%$ in P2 nuclei and $2 \%$ in nuclei with full synapsis (P3/P4) (Fig. S3e). This suggests that synaptic adjustment takes place in the course of the pachytene stage, resulting frequently in nonhomologous synapsis in late pachynema. DMC1 foci were
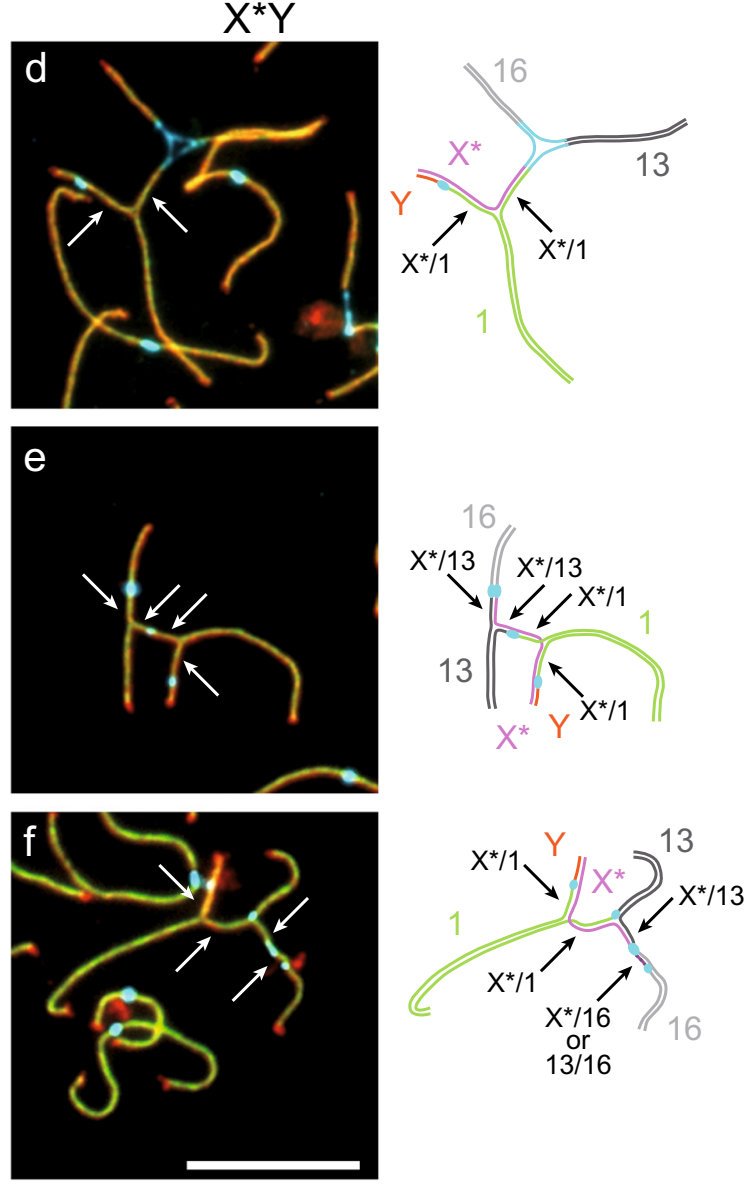

figure on the right of each photograph, the proposed identification of the arms is inferred from their length and the centromere positions. Arrows indicate regions of non-homologous synapsis. Stars indicate nonsynapsed regions inferred to belong to $\mathrm{XX}^{*}$ chromosome arms. Scale bar $=10 \mu \mathrm{m}$. g Distribution of the number of centromere signals on the quadrivalent in fully synapsed ( $\mathrm{P} 3$ and $\mathrm{P} 4)$ pachytene oocytes from $\mathrm{XX}^{*}$ and $\mathrm{X}^{*} \mathrm{Y}$ females. Oocyte numbers: $\mathrm{XX} *, n=267 ; \mathrm{X}^{*} \mathrm{Y}, n=137$

essentially absent from the autosomal bivalents in the rest of the pachytene nuclei, but were detected specifically on unsynapsed and/or non-homologously synapsed regions in a large fraction of nuclei $(47 \%, 59 \%$, and $41 \%$ among P1, P2, and P3/P4 nuclei, respectively; Fig. S3b-e). Finally, the percent of nuclei with very few $(<5)$ or no DMC1 foci increased from $18 \%$ in P1 nuclei to 57\% in P3/P4 nuclei (Fig. S3d, e). The correlation between the extent of non-homologous 
Fig. 4 BRCA1 and $\gamma \mathrm{H} 2 \mathrm{AX}$ signals on meiotic chromosome spreads in $\mathrm{XX}^{*}$ and $\mathrm{X}^{*} \mathrm{Y}$ females. a-f Chromosome spreads of oocytes stained with antibodies against centromere proteins (CEN, CREST serum, light blue), a meiotic chromosome axis marker (SYCP3, red), BRCA1 (green), and $\gamma \mathrm{H} 2 \mathrm{AX}$ (blue) Arrows, asynapsed regions (in pachytene stage; see text) covered by BRCA1 and $\gamma \mathrm{H} 2 \mathrm{AX}$.

Arrowheads, fully synapsed regions covered by BRCA1 and $\gamma \mathrm{H} 2 \mathrm{AX}$. The genotype and meiotic stage are indicated in the diagram. Late Zyg, late zygotene stage; Mid Zyg, mid-zygotene stage; $\mathrm{P} 1, \mathrm{P} 3$, and $\mathrm{P} 4$ as defined in the legend to Fig. 2. Scale bar = $10 \mu \mathrm{m}$
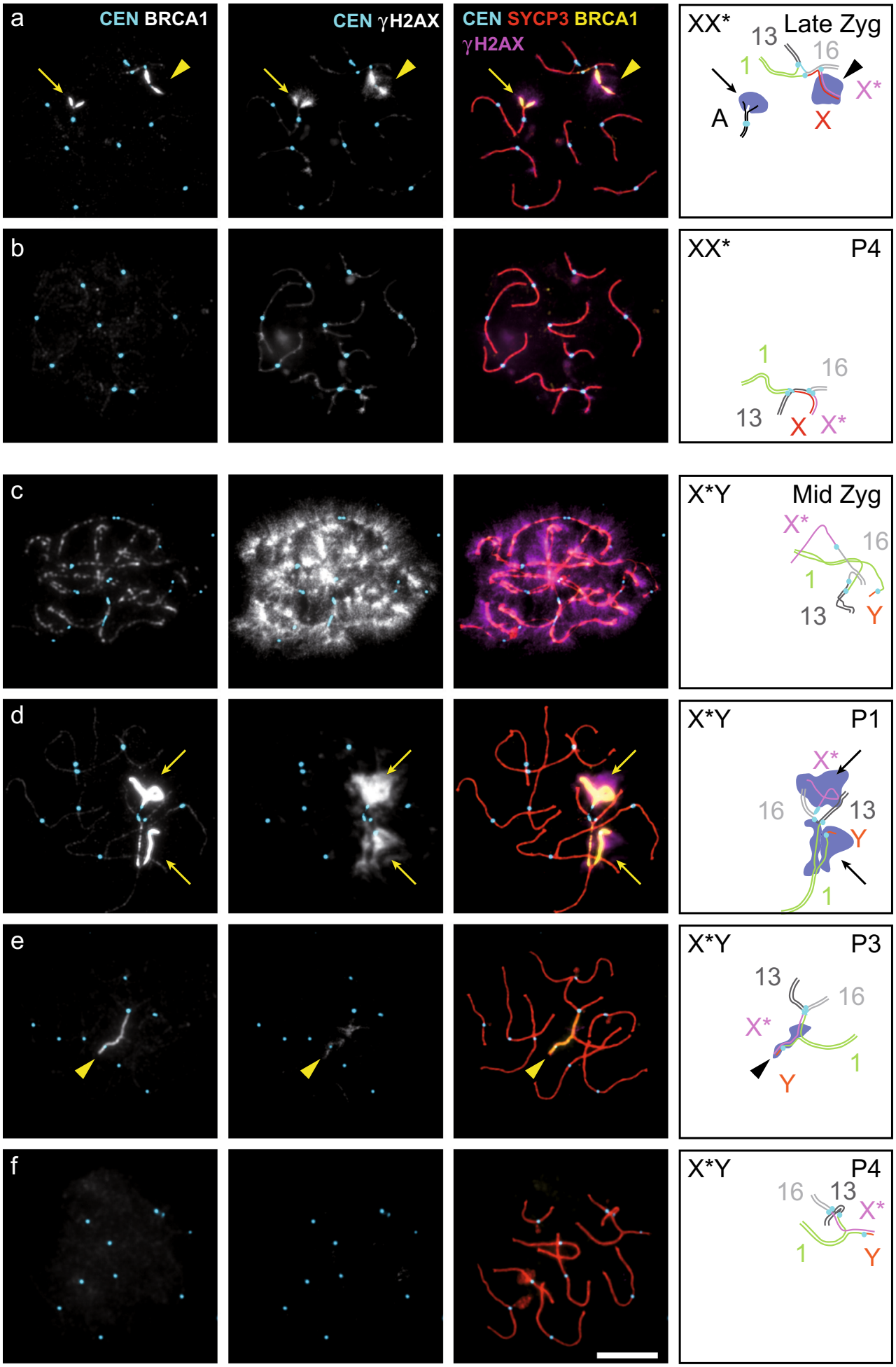

synapsis and the loss of DMC1 foci supports the view that DSB remain unrepaired in regions of asynapsis and nonhomologous synapsis until relatively late in the course of pachytene stage, but that they are eventually repaired before the end of pachynema in a majority of nuclei.

MLH1 is involved in the resolution of about $90 \%$ of crossovers in mice, and is a cytological marker of crossovers on pachytene chromosomes (Baker et al. 1996; Woods et al. 1999; Marcon and Moens 2003; Kolas et al. 2005b; Guillon et al. 2005). One chiasma per bivalent is required to ensure the segregation of every chromosome pair at first meiotic division, a rule referred to as the obligatory crossover. Analysis of MLH1 foci on pachytene nuclei from $\mathrm{XX}, \mathrm{XX}^{*}$, and $\mathrm{X} * \mathrm{Y}$ females (Fig. 5a-d) showed that as expected, most nuclei from 
Fig. 5 Formation of MLH1 foci in $\mathrm{XX}, \mathrm{XX}^{*}$, and $\mathrm{X} * \mathrm{Y}$ females. a-d Chromosome spreads of oocytes stained with antibodies against centromere proteins (CEN, CREST serum, blue), a meiotic chromosome axis marker (SYCP3, red), and MLH1 (green). a XX nucleus with 18 MLH1 foci, $\mathbf{b}$ XX* nucleus with 17 MLH1 foci, and $\mathbf{c}, \mathbf{d} X^{*} Y$ nuclei with 18 and 16 MLH1 foci. Scale bar $=10 \mu \mathrm{m}$. e Number of MLH1 foci in pachytene nuclei displaying at least one MLH1 focus on every bivalent. $\mathbf{f}$ Distribution of the number of MLH1 foci per arm on the bivalents and the quadrivalent in $\mathrm{XX}, \mathrm{XX} *$, and $\mathrm{X}^{*} \mathrm{Y}$ females $\left(\mathrm{X}^{*}\right.$ $\mathrm{Y}$ arm excluded in $\mathrm{X}^{*} \mathrm{Y}$ females). $g$ Distribution of the number of quadrivalent arms with $\geq 1$ MLH1 focus in $\mathrm{XX}^{*}$ and $\mathrm{X}^{*} \mathrm{Y}$ oocytes. Oocyte numbers (e-g): $\mathrm{XX}, n=$ $105 ; \mathrm{XX}^{*}, n=164 ; \mathrm{X}^{*} \mathrm{Y}, n=92$
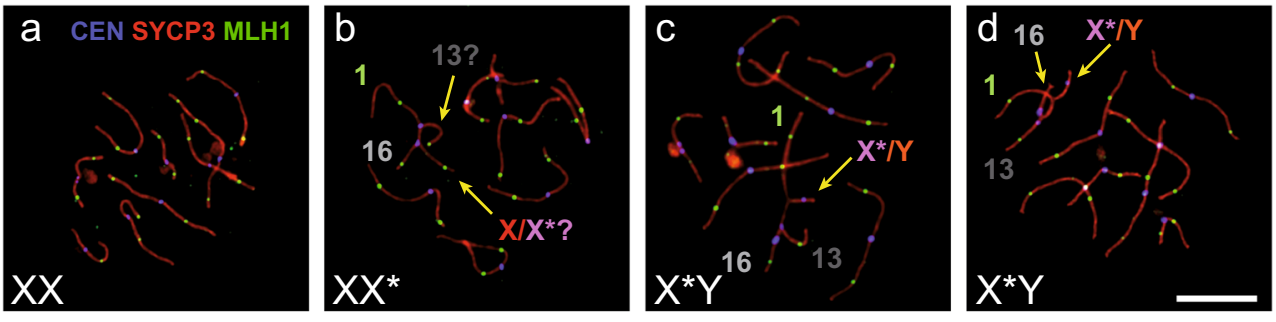

e
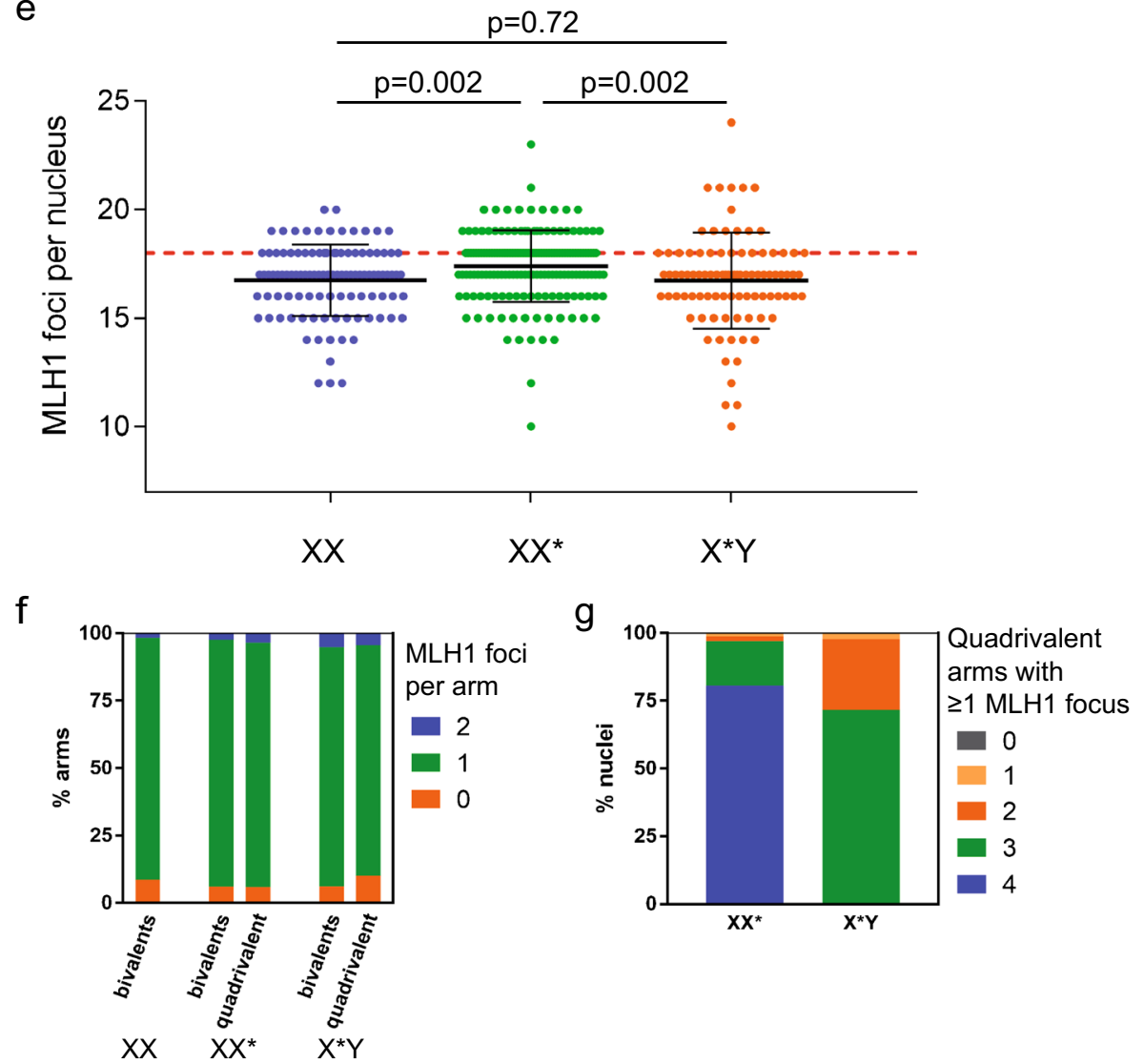

than 1 focus on each of the 18 chromosome arms. While $88.5 \%$ of the arms displayed one MLH1 focus, $10 \%$ and $1.5 \%$ had zero and two foci, respectively (Fig. 5f).

The overall number of MLH1 foci was slightly higher in $\mathrm{XX}^{*}$ than in XX females (17.4 on average; Table 1 and Fig. $5 \mathrm{e})$, with a single focus on most chromosome arms. Given the small number of mice and the variation between them, the biological significance of the small difference cannot be assessed (Fig. S4). The proportion of chromosome arms with
Table 1 MLH1 foci in XX, XX*, and $\mathrm{X}^{*} \mathrm{Y}$ pachytene oocytes

\begin{tabular}{|c|c|c|c|c|}
\hline & & $\mathrm{XX}$ & $\mathrm{XX}^{*}$ & $\mathrm{X}^{*} \mathrm{Y}$ \\
\hline \multicolumn{2}{|l|}{ Total number of nuclei } & 111 & 167 & 102 \\
\hline \multicolumn{2}{|c|}{ Number of nuclei with MLH1 foci on every bivalent } & 105 & 164 & 92 \\
\hline \multicolumn{2}{|l|}{ MLH1 foci per nucleus (mean \pm SD) } & $16.7 \pm 1.7$ & $17.4 \pm 1.6$ & $16.7 \pm 2.2$ \\
\hline \multirow[t]{2}{*}{ MLH1 foci per arm $($ mean \pm SD) } & —bivalents & $0.93 \pm 0.09$ & $0.96 \pm 0.10$ & $0.92 \pm 0.14$ \\
\hline & —quadrivalent & n.a. & $0.98 \pm 0.17$ & $0.95 \pm 0.22$ \\
\hline
\end{tabular}


zero, one, or two foci was not different on the 14 bivalent arms and on the four arms of the quadrivalent (Fig. $5 \mathrm{f} ; \chi^{2}=1.84$, $p=0.40)$. Therefore, the formation of a crossover, marked by MLH1, was not hindered by the formation of a quadrivalent. In addition, this suggests that a MLH1 focus forms as frequently on the $\mathrm{X} / \mathrm{X}^{*}$ chromosome pair as on the autosomal arms of the quadrivalent, an assumption further supported by the finding that $80 \%$ of quadrivalents had MLH1 foci on the four arms. As non-homologous synapsis was revealed by separate centromere signals in about half of $\mathrm{XX}^{*}$ pachytene nuclei (see Fig. 3), crossovers in these intervals of nonhomologous synapsis could hinder the accurate segregation of chromosomes, leading to deleterious consequences, such as aneuploidy. Thus, it is noteworthy that we did not detect any MLH1 focus on intervals between separate centromere signals.

The mean number of MLH1 foci in $\mathrm{X}^{*} \mathrm{Y}$ females (16.7 per nucleus) was similar to that in XX, and slightly less than in $\mathrm{XX}^{*}$ females (Table 1, Fig. 5e and Fig. S4). One could notice that we did not detect any MLH1 focus on the $\mathrm{X}^{*} / \mathrm{Y}$ arm of the quadrivalent ( 0 out of 92). Similarly to $\mathrm{XX}^{*}$, we did not found any MLH1 focus on any interval engaged in an identified nonhomologous synapsis.

In $\mathrm{XX}^{*}$ nuclei, the same proportion of bivalent and quadrivalent arms had no MLH1 focus (138 among 2296 bivalent arms and 39 among 656 quadrivalent arms; $p=1$, two-tailed Fisher's exact test). Conversely, in $\mathrm{X}^{*} \mathrm{Y}$ nuclei, the proportion of quadrivalent arms without any MLH1 focus was significantly higher (Fig. 5f, g; 78 among 1288 bivalent arms and 28 among 276 autosomal quadrivalent arms; $p=0.018)$. This might have deleterious consequences on the accurate segregation of chromosomes, and ultimately on the formation of functional gametes. Indeed, while a single chiasma is enough to ensure the segregation of one pair of homologous chromosomes, chiasmata on at least three arms of a quadrivalent are required to link the four chromosomes and direct their segregation accurately. Ninety-seven percent of $\mathrm{XX}^{*}$ nuclei had MLH1 foci on three or four arms (Fig. 5g). Conversely, 28\% of $\mathrm{X}^{*} \mathrm{Y}$ pachytene oocyte nuclei had MLH1 foci on only one or two arms of the quadrivalent, because MLH1 foci were restricted to only three autosomal arms that display a higher probability of not having one MLH1 focus.

\section{Discussion}

In mammals, meiotic trivalents following sex-autosome translocations are not that uncommon (e.g., Fredga 1970; Ratomponirina et al. 1986; Dobigny et al. 2004; Deuve et al. 2008; Veyrunes et al. 2014; Rahn et al. 2016; Vozdova et al. 2016), suggesting common mechanisms to face the meiotic hurdles. In contrast, sex chromosome multivalents derived from four or more chromosomes are extremely rare, since they greatly interfere with meiotic progression and often cause infertility (Gruetzner et al. 2006). Within Artiodactyla, a chain of four is characteristic of the genera Nanger and Eudorcas following the translocations of the $\mathrm{X}$ and $\mathrm{Y}$ chromosomes on different autosomes (Vozdova et al. 2016), and in the black muntjac Muntiacus crinifrons, complex rearrangements between sex chromosomes and autosomes have contributed to the origin of a pentavalent at meiosis (Huang et al. 2006). Among the New World howler monkeys, some species of the genus Alouatta show a quadrivalent due to translocations between the $\mathrm{Y}$ and autosomes, and an additional rearrangement has led to a pentavalent in A. guariba (Rahn et al. 1996; Mudry et al. 2001; Steinberg et al. 2017). The most striking multivalents are observed in monotremes, with sex chromosome chains of nine in echidna and ten in platypus (Rens et al. 2004, 2007; Daish et al. 2009; Casey et al. 2017). Nevertheless, because of the male heterogamety in mammals, the formation of sex chromosome multivalents is usually restricted to male meiosis, whereas in females the $X_{n}$ chromosomes are present at the homozygous state, pair and complete a normal homologous synapsis. Here, we describe for the first time sex chromosome multivalents in mammalian female meiosis due to an unusual sex determination system that leads to an unprecedented meiotic behavior, where each of the three female genotypes is characterized by specific meiotic configurations: sex chromosome bivalents in $\mathrm{XX}$, and different sex chromosome quadrivalents in $\mathrm{XX}^{*}$ and $\mathrm{X}^{*} \mathrm{Y}$ females. We described and unequivocally demonstrated the presence and detailed features of the multivalents. The evolution of such atypical sex chromosome system represents a paradox for at least two reasons. First, in mammals, most XY females are sterile due to meiotic defects (caused by the lack of the $\mathrm{X}$ chromosome partner and the presence of a $\mathrm{Y}$ chromosome), poor XY oocyte survival, and loss of unviable YY embryos (Villemure et al. 2007; Alton et al. 2008; $\mathrm{Xu}$ et al. 2012; Vernet et al. 2014; Parma et al. 2016). Second, autosomal meiotic multivalents (chains or rings) often cause infertility in mammals, and those involving the sex chromosomes usually further reduce fertility (review in Gruetzner et al. 2006). Previously, in laboratory conditions, we found that fertility was comparable in $\mathrm{XX}$ and $\mathrm{XX}^{*}$ females and more unexpectedly, that the reproductive performance of $X^{*} Y$ females was even higher than that of females of the other two genotypes (Saunders et al. 2014). This advantage is explained by their higher probability of breeding, earlier breeding onset, larger litter size, and higher ovulation rate. However, how $\mathrm{XX}^{*}$ and especially $\mathrm{X}^{*} \mathrm{Y}$ females manage to bypass the meiotic constraints and to produce a big enough pool 
of functional oocytes to ensure normal fertility remained unknown.

Mus minutoides $\mathrm{XX}^{*}$ oocytes need to manage the formation of a quadrivalent composed of $\mathrm{Rb}(\mathrm{X} .1), \mathrm{Rb}(1.13)$, $\mathrm{Rb}(13.16)$, and $\mathrm{Rb}\left(\mathrm{X}^{*} .16\right)$ during meiotic prophase. At the first meiotic division, an alternate segregation of the four chromosomes is necessary to produce balanced gametes of two types: $\mathrm{Rb}(\mathrm{X} .1) \mathrm{Rb}(13.16)$ and $\mathrm{Rb}(1.13)$ $\mathrm{Rb}\left(\mathrm{X}^{*} .16\right)$. The latter type of gametes produces only females $\left(\mathrm{XX}^{*}\right.$ and $\left.\mathrm{X}^{*} \mathrm{Y}\right)$ and carries the two specific chromosomal variants. We found that the meiotic configuration adopted by this quadrivalent is compatible with minimal disruption of the meiotic process. Indeed, the quadrivalent adopts a closed configuration where all chromosome axes are fully synapsed. Moreover, in quadrivalent arms, crossovers occur at the same frequency as in bivalent arms, and consequently, 97\% of $\mathrm{XX}^{*}$ quadrivalents have at least one MLH1 focus on three or four arms, which is sufficient to ensure the reductional segregation of the four chromosomes at first meiotic division. Although short centromere-proximal regions engage frequently in non-homologous synapsis, this might not have any direct consequence on the meiotic process, apart from preventing exchanges within these restricted intervals.

The $\mathrm{X}^{*} \mathrm{Y}$ quadrivalent [Rb(Y.1), Rb(1.13), Rb(13.16), $\left.\mathrm{Rb}\left(\mathrm{X}^{*} .16\right)\right]$ faces additional hurdles to successfully complete meiotic divisions and to generate functional gametes and viable embryos. First, homologous pairing and synapsis are more affected in the $X^{*} \mathrm{Y}$ quadrivalent, because of the lack of homology and the large-size difference between the $\mathrm{X}^{*}$ and $\mathrm{Y}$ chromosomes. We found that $\mathrm{X}^{*} \mathrm{Y}$ pachytene oocyte nuclei can adopt an open chain configuration with asynapsed $\mathrm{X}^{*}$ and $\mathrm{Y}$ arms (P1 nuclei; Fig. $2 \mathrm{~b}$ ) or a closed configuration in which $\mathrm{X}^{*}$ and $\mathrm{Y}$ associate through non-homologous synapsis (P3 and P4 nuclei). Our data do not allow determining which category of oocytes ensures the fertility of $\mathrm{X}^{*} \mathrm{Y}$ females. Indeed, in M. musculus, meiosis and fertility can be affected by the inappropriate silencing of $\mathrm{X}$-linked genes on asynapsed $\mathrm{X}$ chromosome, or by the inappropriate expression of $\mathrm{Y}$ linked genes when the $\mathrm{Y}$ chromosome is engaged in synapsis (Vernet et al. 2014; Cloutier et al. 2015). The mechanism of transcriptional silencing of unsynapsed chromosomes appears to be active in $M$. minutoides pachytene oocytes, as inferred from BRCA1 and $\gamma \mathrm{H} 2 \mathrm{AX}$ staining. However, in M. musculus, this transcriptional silencing is less efficient in oocytes than in spermatocytes (Taketo and Naumova 2013; Cloutier et al. 2016), and it cannot be excluded that the expression level of X-linked genes from unsynapsed $\mathrm{X}^{*}$ is sufficient. Alternatively, expression of Y-linked genes from synapsed $\mathrm{Y}$ chromosome could be sufficiently reduced, or harmless in $M$. minutoides $\mathrm{X}^{*} \mathrm{Y}$ oocytes.
A second hurdle comes from the scarcity of crossovers on the $\mathrm{X}^{*} \mathrm{Y}$ quadrivalent, of which a high proportion $(28 \%)$ had fewer than the minimum of three arms with at least one MLH1 focus (Fig. $5 \mathrm{~g}$ ) that is necessary to tie the four chromosomes together and ensure the transmission of the euploid load of every arm. Some mechanisms might partially compensate for the shortage of MLH1-dependent crossovers. First, the proportion of quadrivalents with fewer than three crossovers might be overestimated because of the formation of MLH1independent crossovers, which are estimated to account for about $10 \%$ of all crossovers in M. musculus (Baker et al. 1996; Woods et al. 1999; Marcon and Moens 2003; Kolas et al. 2005b; Guillon et al. 2005). Moreover, the segregation of specific chromosome pairs or of an achiasmate univalent chromosome might deviate from random in mouse oocytes (LeMaire-Adkins and Hunt 2000; Lampson and Black 2017; $\mathrm{Wu}$ et al. 2018). One might also speculate on a mechanism promoting the segregation of achiasmate $\mathrm{X}^{*}$ and $\mathrm{Y}$ chromosomes, somehow similar to the mechanism ensuring the male meiosis I segregation of achiasmate $\mathrm{X}$ and $\mathrm{Y}$ chromosomes in closely related species from the subgenus Nannomys (Jotterand-Bellomo 1981; Britton-Davidian et al. 2012). Altogether, our results suggest that meiosis in $\mathrm{X}^{*} \mathrm{Y}$ oocytes is largely impeded by synapsis and recombination deficiencies; albeit, $\mathrm{X}^{*} \mathrm{Y}$ female fertility is as good as, if not better, that of XX and $X^{*}$ females (Saunders et al. 2014). This raises questions about how $\mathrm{X} * \mathrm{Y}$ females manage to produce enough functional gametes to compensate those meiotic defects and the costly loss of the YY embryos. Remarkably however, pedigree analysis from our colony suggests that Ycarrying eggs are produced and fertile (Saunders et al. 2014 and FV, unpublished data). One main question is thus to understand how oocytes lacking the thousand of X-specific genes can be functional in this species.

Interestingly, an $\mathrm{X}^{*}$ chromosome that feminizes $\mathrm{X}^{*} \mathrm{Y}$ embryos also occurs independently in the wood lemming Myopus schisticolor. However, in this species, the meiotic behavior of sex-reversed females is completely different. The $\mathrm{Y}$ chromosome is eliminated from the $\mathrm{X}^{*} \mathrm{Y}$ female germ line and replaced with a copy of the $X^{*}$ through a mitotic double non-disjunction mechanism. Consequently, all oocytes are $\mathrm{X}^{*} \mathrm{X}^{*}$ and only $\mathrm{X}^{*}$-carrying gametes are produced (Fredga 1994). This system allows avoiding the meiotic problems inherent to heteromorphic sex chromosomes in mammalian females (e.g., asynapsis of the $\mathrm{X}$ and $\mathrm{Y}$ chromosomes, absence of an $\mathrm{X}$ partner, loss of YY embryos, and functionality of Y-carrying eggs). However, although pairing between two $X^{*}$ should be less problematic than between the $\mathrm{X}^{*}$ and $\mathrm{Y}$ in $M$. minutoides, the frequency of oocytes with numerical abnormalities is extremely high in $M$. schisticolor (Akhverdyan and Fredga 2001), while we did not detect any in the pygmy mouse. 
Finally, we reported a very high frequency of nonhomologous synapsis (in all $\mathrm{X}^{*} \mathrm{Y}$ pachytene nuclei with full synapsis and about half of the $\mathrm{XX}^{*}$ ) that involves several centromere-proximal regions (Fig. 3). We thus expect a strong reduction in female recombination in these regions that might possibly extend beyond the intervals experiencing nonhomologous synapsis. Indeed, proximal recombination is reduced in autosomal pentavalents in the house mouse, notably due to the tendency for axial elements to remain separated near the centromeres (Merico et al. 2013). Hence, former autosomes that are now physically linked to sex chromosomes may also be sheltered from recombination in their proximal regions due to the WART. These dramatic changes in the inheritance and recombination patterns are expected to have profound consequences in gene content, sequence, and expression (e.g., Charlesworth et al. 2005; Bachtrog et al. 2011; Bachtrog 2013). If the suppression of recombination is confirmed, we predict signs of neosexualization (e.g., sexbiased gene expression, accumulation of repetitive elements, rapid molecular evolution under positive selection, or degeneration) especially in the proximal region of the chromosome $\mathrm{Rb}(1.13)$ which cosegregates with the $\mathrm{Rb}\left(\mathrm{X}^{*} .16\right)$ and is female-specific.

Many studies on the role of the meiotic machinery and its influence on fertility have been performed mainly using transgenic mice in which the sex chromosome complement was genetically manipulated (e.g., Vernet et al. 2014; Cloutier et al. 2015), and very few using species with unusual sex chromosome systems shaped by natural selection. Investigating the meiotic behavior in nonlaboratory species, such as the African pygmy mouse, the mole voles Ellobius talpinus and E. tancrei where males are XX (Matveevsky et al. 2016), and in other species with multiple-sex-chromosome systems (e.g., Rahn et al. 2016; Vozdova et al. 2016) might contribute to better understand the mechanisms that ensure proper sex chromosome pairing, synapsis, recombination, transcriptional inactivation, and balanced segregation.

Acknowledgements We thank Satoshi Namekawa for the anti-BRCA1 antibody, Marie Challe for her help in maintaining the breeding colony, and Julie Perez for genotyping some animals. We are especially indebted to the animal breeding facility of the University of Montpellier (CECEMA), the CytoEvol facilities of ISEM (labex CeMEB) and the imaging facility MRI, member of the national infrastructure FranceBioImaging infrastructure supported by the French National Research Agency (ANR-10-INBS-04, «Investments for the future»).

Funding information This work was supported by grants from the Centre National pour la Recherche Scientifique (CNRS) and by the European Research Council (ERC) Executive Agency under the European Community's Seventh Framework Programme (FP7/ 2007-2013 grant agreement no. 322788) to B.d.M. F.V. was funded by the French National Research Agency (ANR grant "SEXYMUS," no. 10-JCJC-1605) and the Del Duca Foundation from Institut de France.

\section{References}

Akhverdyan M, Fredga K (2001) EM studies of female meiosis in wood lemmings with different sex chromosome constitutions. J Exp Zool 290:504-516

Alton M, Lau MP, Villemure M, Taketo T (2008) The behavior of the Xand Y-chromosomes in the oocyte during meiotic prophase in the B6.YTIRsex-reversed mouse ovary. Reproduction. 135:241-252

Amleh A, Smith L, Chen H-Y, Taketo T (2000) Both nuclear and cytoplasmic components are defective in oocytes of the B6.YTIR sexreversed female mouse. Dev Biol 219:277-286. https://doi.org/10. 1006/dbio. 1999.9600

Arboleda VA, Fleming A, Barseghyan H, Délot E, Sinsheimer JS, Vilain E (2014) Regulation of sex determination in mice by a non-coding genomic region. Genetics 197:885-897. https://doi.org/10.1534/ genetics.113.160259

Baarends WM, Wassenaar E, van der Laan R, Hoogerbrugge J, SleddensLinkels E, Hoeijmakers JHJ, de Boer P, Grootegoed JA (2005) Silencing of unpaired chromatin and histone H2A ubiquitination in mammalian meiosis. Mol Cell Biol 25:1041-1053

Bachtrog D (2013) Y-chromosome evolution: emerging insights into processes of Y-chromosome degeneration. Nat Rev Genet 14:113-124. https://doi.org/10.1038/nrg3366

Bachtrog D, Kirkpatrick M, Mank JE, McDaniel SF, Pires JC, Rice W, Valenzuela N (2011) Are all sex chromosomes created equal? Trends Genet 27:350-357. https://doi.org/10.1016/j.tig.2011.05.005

Baker SM, Plug AW, Prolla TA, Bronner CE, Harris AC, Yao X, Christie DM, Monell C, Arnheim N, Bradley A, Ashley T, Liskay RM (1996) Involvement of mouse Mlh1 in DNA mismatch repair and meiotic crossing over. Nat Genet 13:336-342

Baudat F, Imai Y, de Massy B (2013) Meiotic recombination in mammals: localization and regulation. Nat Rev Genet 14:794-806. https://doi.org/10.1038/nrg3573

Borodin PM, Basheva EA, Torgasheva AA, Dashkevich OA, Golenishchev FN, Kartavtseva IV, Mekada K, Dumont BL (2012) Multiple independent evolutionary losses of XY pairing at meiosis in the grey voles. Chromosom Res 20:259-268. https://doi.org/10. 1007/s10577-011-9261-0

Britton-Davidian J, Robinson TJ, Veyrunes F (2012) Systematics and evolution of the African pygmy mice, subgenus Nannomys: a review. Acta Oecol 42:41-49. https://doi.org/10.1016/j.actao. 2012.01.001

Burgoyne PS, Baker TG (1981) Oocyte depletion in XO mice and their XX sibs from 12 to 200 days post partum. J Reprod Fertil 61:207-212

Burgoyne PS, Baker TG (1985) Perinatal oocyte loss in XO mice and its implications for the aetiology of gonadal dysgenesis in XO women. J Reprod Fertil 75:633-645

Burgoyne PS, Mahadevaiah SK, Turner JM (2009) The consequences of asynapsis for mammalian meiosis. Nat Rev Genet 10:207-216

Casey AE, Daish TJ, Barbero JL, Grützner F (2017) Differential cohesin loading marks paired and unpaired regions of platypus sex chromosomes at prophase I. Sci Rep 7:4217. https://doi.org/10.1038/ s41598-017-04560-5

Charlesworth D, Charlesworth B, Marais G (2005) Steps in the evolution of heteromorphic sex chromosomes. Heredity (Edinb) 95:118-128. https://doi.org/10.1038/sj.hdy.6800697

Cloutier JM, Mahadevaiah SK, ElInati E, Nussenzweig A, Tóth A, Turner JMA (2015) Histone H2AFX links meiotic chromosome asynapsis to prophase I oocyte loss in mammals. PLoS Genet 11: e1005462. https://doi.org/10.1371/journal.pgen.1005462

Cloutier JM, Mahadevaiah SK, ElInati E, Tóth A, Turner J (2016) Mammalian meiotic silencing exhibits sexually dimorphic features. Chromosoma 125:215-226. https://doi.org/10.1007/ s00412-015-0568-z 
Daish T, Casey A, Grützner F (2009) Platypus chain reaction: directional and ordered meiotic pairing of the multiple sex chromosome chain in Ornithorhynchus anatinus. Reprod Fertil Dev 21:976-984. https://doi.org/10.1071/RD09085

de la Fuente R, Parra MT, Viera A, Calvente A, Gómez R, Suja JÁ, Rufas JS, Page J (2007) Meiotic pairing and segregation of achiasmate sex chromosomes in eutherian mammals: the role of SYCP3 protein. PLoS Genet 3:e198. https://doi.org/10.1371/journal.pgen.0030198

Deuve JL, Bennett NC, Ruiz-Herrera A, Waters PD, Britton-Davidian J, Robinson TJ (2008) Dissection of a Y-autosome translocation in Cryptomys hottentotus (Rodentia, Bathyergidae) and implications for the evolution of a meiotic sex chromosome chain. Chromosoma 117:211-217. https://doi.org/10.1007/s00412007-0140-6

Dobigny G, Ozouf-Costaz C, Bonillo C, Volobouev V (2004) Viability of $\mathrm{X}$-autosome translocations in mammals: an epigenomic hypothesis from a rodent case-study. Chromosoma 113:34-41. https://doi.org/ 10.1007/s00412-004-0292-6

Eicher EM, Washburn LL, Whitney JB, Morrow KE (1982) Mus poschiavinus $\mathrm{Y}$ chromosome in the $\mathrm{C} 57 \mathrm{BL} / 6 \mathrm{~J}$ murine genome causes sex reversal. Science 217:535-537

Fredga K (1970) Unusual sex chromosome inheritance in mammals. Philos Trans R Soc Lond Ser B Biol Sci 259:15-36

Fredga K (1994) Bizarre mammalian sex-determining mechanisms. In: Short R, Balaban E (eds) The differences between the sexes. Cambridge University Press, Cambridge, pp 419-431

Grey C, Baudat F, de Massy B (2009) Genome-wide control of the distribution of meiotic recombination. PLoS Biol 7:e35

Gruetzner F, Ashley T, Rowell DM, Marshall Graves JA (2006) How did the platypus get its sex chromosome chain? A comparison of meiotic multiples and sex chromosomes in plants and animals. Chromosoma 115:75-88. https://doi.org/10.1007/s00412-005-0034-4

Gubbay J, Vivian N, Economou A, Jackson D, Goodfellow P, LovellBadge R (1992) Inverted repeat structure of the Sry locus in mice. Proc Natl Acad Sci U S A 89:7953-7957

Guillon H, Baudat F, Grey C, Liskay RM, de Massy B (2005) Crossover and noncrossover pathways in mouse meiosis. Mol Cell 20:563573. https://doi.org/10.1016/j.molcel.2005.09.021

Huang L, Chi J, Wang J, Nie W, Su W, Yang F (2006) High-density comparative BAC mapping in the black muntjac (Muntiacus crinifrons): molecular cytogenetic dissection of the origin of MCR $1 \mathrm{p}+4$ in the X1X2Y1Y2Y3 sex chromosome system. Genomics 87: 608-615. https://doi.org/10.1016/j.ygeno.2005.12.008

Hunter N (2015) Meiotic recombination: the essence of heredity. Cold Spring Harb Perspect Biol 7:a016618. https://doi.org/10.1101/ cshperspect.a016618

Ichijima $\mathrm{Y}$, Ichijima $\mathrm{M}$, Lou Z, Nussenzweig A, Camerini-Otero RD, Chen J, Andreassen PR, Namekawa SH (2011) MDC1 directs chromosome-wide silencing of the sex chromosomes in male germ cells. Genes Dev 25:959-971. https://doi.org/10.1101/gad.2030811

Jotterand-Bellomo M (1981) Le caryotype et la spermatogénèse de Mus setulosus (bandes Q, C, G et coloration argentique). Genetica 56: 217-227. https://doi.org/10.1007/BF00057563

Kauppi L, Barchi M, Lange J, Baudat F, Jasin M, Keeney S (2013) Numerical constraints and feedback control of double-strand breaks in mouse meiosis. Genes Dev 27:873-886. https://doi.org/10.1101/ $\operatorname{gad} .213652 .113$

Kolas NK, Marcon E, Crackower MA, Höög C, Penninger JM, Spyropoulos B, Moens PB (2005a) Mutant meiotic chromosome core components in mice can cause apparent sexual dimorphic endpoints at prophase or X-Y defective male-specific sterility. Chromosoma 114:92-102

Kolas NK, Svetlanov A, Lenzi ML, Macaluso FP, Lipkin SM, Liskay RM, Greally J, Edelmann W, Cohen PE (2005b) Localization of MMR proteins on meiotic chromosomes in mice indicates distinct functions during prophase I. J Cell Biol 171:447-458
Lampson MA, Black BE (2017) Cellular and molecular mechanisms of centromere drive. Cold Spring Harb Symp Quant Biol 82:249-257. https://doi.org/10.1101/sqb.2017.82.034298

Laval SH, Glenister PH, Rasberry C, Thornton CE, Mahadevaiah SK, Cooke HJ, Burgoyne PS, Cattanach BM (1995) Y chromosome short arm-Sxr recombination in $\mathrm{XSxr} / \mathrm{Y}$ males causes deletion of Rbm and XY female sex reversal. Proc Natl Acad Sci U S A 92: 10403-10407

LeMaire-Adkins R, Hunt PA (2000) Nonrandom segregation of the mouse univalent $\mathrm{X}$ chromosome: evidence of spindle-mediated meiotic drive. Genetics 156:775-783

Mahadevaiah SK, Lovell-Badge R, Burgoyne PS (1993) Tdy-negative $\mathrm{XY}, \mathrm{XXY}$ and XYY female mice: breeding data and synaptonemal complex analysis. J Reprod Fertil 97:151-160

Marcon E, Moens P (2003) MLH1p and MLH3p localize to precociously induced chiasmata of okadaic-acid-treated mouse spermatocytes. Genetics 165:2283-2287

Matveevsky S, Bakloushinskaya I, Kolomiets O (2016) Unique sex chromosome systems in Ellobius: how do male XX chromosomes recombine and undergo pachytene chromatin inactivation? Sci Rep 6: 29949. https://doi.org/10.1038/srep29949

Merico V, Giménez MD, Vasco V, Zuccotti M, Searle JB, Hauffe HC, Garagna S, (2013) Chromosomal speciation in mice: a cytogenetic analysis of recombination. Chromosome Res 21:523-533. https:// doi.org/10.1007/s10577-013-9377-5

Moens PB, Chen DJ, Shen Z, Kolas N, Tarsounas M, Heng HHQ, Spyropoulos B (1997) Rad51 immunocytology in rat and mouse spermatocytes and oocytes. Chromosoma 106:207-215

Mudry MD, Rahn IM, Solari AJ (2001) Meiosis and chromosome painting of sex chromosome systems in Ceboidea. Am J Primatol 54:6578. https://doi.org/10.1002/ajp.1013

Parma P, Veyrunes F, Pailhoux E (2016) Sex reversal in non-human placental mammals. Sex Dev 10:326-344. https://doi.org/10.1159/ 000448361

Peters AH, Plug AW, van Vugt MJ, de Boer P (1997) A drying-down technique for the spreading of mammalian meiocytes from the male and female germline. Chromosom Res 5:66-68

Rahn MI, Mudry M, Merani MS, Solari AJ (1996) Meiotic behavior of the X1X2Y1Y2 quadrivalent of the primate Alouatta caraya. Chromosom Res 4:350-356

Rahn MI, Noronha RC, Nagamachi CY, Pieczarka JC, Solari AJ, Sciurano RB (2016) Protein markers of synaptic behavior and chromatin remodeling of the neo-XY body in phyllostomid bats. Chromosoma 125:701-708. https://doi.org/10.1007/ s00412-015-0566-1

Ratomponirina C, Viegas-Péquignot E, Dutrillaux B, Petter F, Rumpler Y (1986) Synaptonemal complexes in Gerbillidae: probable role of intercalated heterochromatin in gonosome-autosome translocations. Cytogenet Genome Res 43:161-167. https://doi.org/10.1159/ 000132315

Rens W, Grutzner F, O'Brien PCM et al (2004) From the cover: resolution and evolution of the duck-billed platypus karyotype with an X1Y1X2Y2X3Y3X4Y4X5Y5 male sex chromosome constitution. Proc Natl Acad Sci 101:16257-16261. https://doi.org/10.1073/pnas. 0405702101

Rens W, O'Brien PC, Grutzner F et al (2007) The multiple sex chromosomes of platypus and echidna are not completely identical and several share homology with the avian Z. Genome Biol 8:R243. https://doi.org/10.1186/gb-2007-8-11-r243

Royo H, Polikiewicz G, Mahadevaiah SK, Prosser H, Mitchell M, Bradley A, de Rooij DG, Burgoyne PS, Turner JMA (2010) Evidence that meiotic sex chromosome inactivation is essential for male fertility. Curr Biol 20:2117-2123. https://doi.org/10.1016/j. cub.2010.11.010

Royo H, Prosser H, Ruzankina Y, Mahadevaiah SK, Cloutier JM, Baumann M, Fukuda T, Hoog C, Toth A, de Rooij DG, Bradley 
A, Brown EJ, Turner JMA (2013) ATR acts stage specifically to regulate multiple aspects of mammalian meiotic silencing. Genes Dev 27:1484-1494. https://doi.org/10.1101/gad.219477.113

Saunders PA, Perez J, Rahmoun M, Ronce O, Crochet PA, Veyrunes F (2014) XY females do better than the XX in the African pygmy mouse, Mus minutoides. Evolution 68:2119-2127. https://doi.org/ 10.1111/evo. 12387

Speed RM (1986) Oocyte development in XO foetuses of man and mouse: the possible role of heterologous $\mathrm{X}$-chromosome pairing in germ cell survival. Chromosoma 94:115-124

Steinberg ER, Fortes VB, Rossi LF, Murer L, Lovato M, Merani MS, Mudry MD (2017) Cytogenetic characterization of brown howler monkeys, Alouatta guariba clamitans (Atelidae, Platyrrhini): meiotic confirmation of an X1X1X2X2X3X3/X1X2X3Y1Y2 sex chromosome system. Cytogenet Genome Res 151:131-140. https://doi. org/10.1159/000464375

Subramanian VV, Hochwagen A (2014) The meiotic checkpoint network: step-by-step through meiotic prophase. Cold Spring Harb Perspect Biol 6:a016675. https://doi.org/10.1101/ cshperspect.a016675

Taketo T, Naumova AK (2013) Oocyte heterogeneity with respect to the meiotic silencing of unsynapsed $\mathrm{X}$ chromosomes in the $\mathrm{XY}$ female mouse. Chromosoma 122:337-349. https://doi.org/10.1007/ s00412-013-0415-z

Tarsounas M, Morita T, Pearlman RE, Moens PB (1999) RAD51 and DMC1 form mixed complexes associated with mouse meiotic chromosome cores and synaptonemal complexes. J Cell Biol 147:207-220

Turner JM, Aprelikova O, Xu X et al (2004) BRCA1, histone H2AX phosphorylation, and male meiotic sex chromosome inactivation. Curr Biol 14:2135-2142

Turner JM, Mahadevaiah SK, Fernandez-Capetillo O et al (2005) Silencing of unsynapsed meiotic chromosomes in the mouse. Nat Genet 37:41-47

Vernet N, Szot M, Mahadevaiah SK, Ellis PJI, Decarpentrie F, Ojarikre OA, Rattigan A, Taketo T, Burgoyne PS (2014) The expression of Y-linked Zfy2 in XY mouse oocytes leads to frequent meiosis 2 defects, a high incidence of subsequent early cleavage stage arrest and infertility. Development 141:855866. https://doi.org/10.1242/dev.091165

Veyrunes F, Perez J (2018) X inactivation in a mammal species with three sex chromosomes. Chromosoma 127:261-267. https://doi.org/10. 1007/s00412-017-0657-2

Veyrunes F, Catalan J, Sicard B, Robinson TJ, Duplantier JM, Granjon L, Dobigny G, Britton-Davidian J (2004) Autosome and sex chromosome diversity among the African pygmy mice, subgenus Nannomys (Murinae; Mus). Chromosom Res 12:369-382. https:// doi.org/10.1023/B:CHRO.0000034098.09885.e6

Veyrunes F, Watson J, Robinson TJ, Britton-Davidian J (2007) Accumulation of rare sex chromosome rearrangements in the African pygmy mouse, Mus (Nannomys) minutoides: a whole-arm reciprocal translocation (WART) involving an X-autosome fusion. Chromosom Res 15:223-230. https://doi.org/10.1007/s10577-006-1116-8

Veyrunes F, Catalan J, Tatard C, Cellier-Holzem E, Watson J, Chevret P, Robinson TJ, Britton-Davidian J (2010a) Mitochondrial and chromosomal insights into karyotypic evolution of the pygmy mouse, Mus minutoides, in South Africa. Chromosom Res 18:563-574. https://doi.org/10.1007/s10577-010-9144-9

Veyrunes F, Chevret P, Catalan J, Castiglia R, Watson J, Dobigny G, Robinson TJ, Britton-Davidian J (2010b) A novel sex determination system in a close relative of the house mouse. Proc Biol Sci 277: 1049-1056. https://doi.org/10.1098/rspb.2009.1925

Veyrunes F, Perez J, Borremans B, Gryseels S, Richards LR, Duran A, Chevret P, Robinson TJ, Britton-Davidian J (2014) A new cytotype of the African pygmy mouse Mus minutoides in eastern Africa. Implications for the evolution of sex-autosome translocations. Chromosom Res 22:533-543. https://doi.org/ 10.1007/s10577-014-9440-x

Villemure M, Chen H-Y, Kurokawa M, Fissore RA, Taketo T (2007) The presence of $\mathrm{X}$ - and Y-chromosomes in oocytes leads to impairment in the progression of the second meiotic division. Dev Biol 301:113. https://doi.org/10.1016/j.ydbio.2006.10.034

Vozdova M, Ruiz-Herrera A, Fernandez J, Cernohorska H, Frohlich J, Sebestova H, Kubickova S, Rubes J (2016) Meiotic behaviour of evolutionary sex-autosome translocations in Bovidae. Chromosom Res 24:325-338. https://doi.org/10.1007/s10577-016-9524-x

Woods LM, Hodges CA, Baart E, Baker SM, Liskay M, Hunt PA (1999) Chromosomal influence on meiotic spindle assembly: abnormal meiosis I in female Mlh1 mutant mice. J Cell Biol 145:1395-1406

Wu T, Lane SIR, Morgan SL, Jones KT (2018) Spindle tubulin and MTOC asymmetries may explain meiotic drive in oocytes. Nat Commun 9:2952. https://doi.org/10.1038/s41467-018-05338-7

Xu B, Obata Y, Cao F, Taketo T (2012) The presence of the Y-chromosome, not the absence of the second X-chromosome, alters the mRNA levels stored in the fully grown XY mouse oocyte. PLoS One 7:e40481. https://doi.org/10.1371/journal.pone.0040481

Publisher's note Springer Nature remains neutral with regard to jurisdictional claims in published maps and institutional affiliations. 
Figure S1
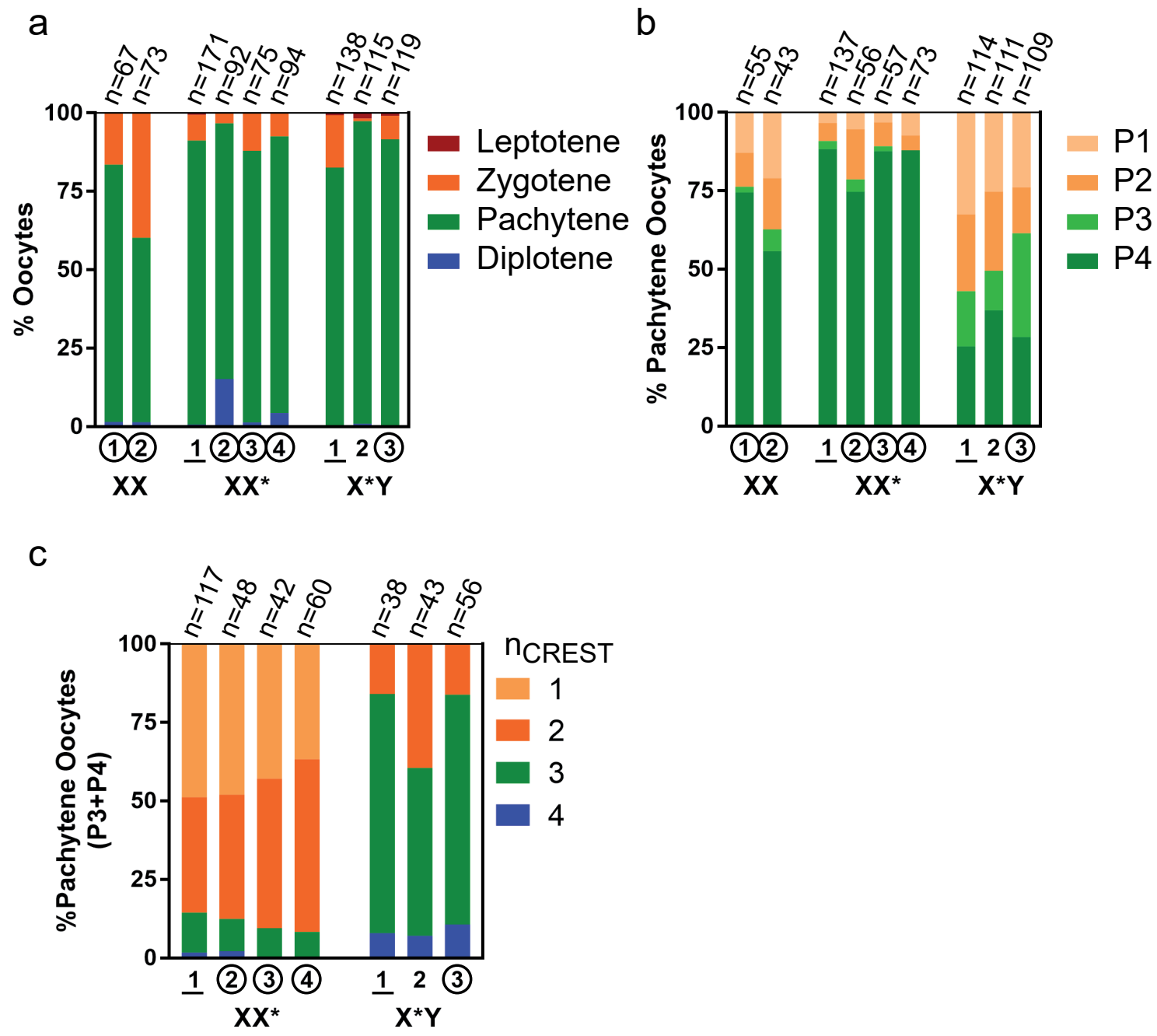
Figure S1. Synapsis of the sex-autosome quadrivalents in $\mathrm{XX}^{*}$ and $\mathrm{X} * \mathrm{Y}$ females. (a) Distribution of oocytes from $\mathrm{XX}, \mathrm{XX}^{*}$ and $\mathrm{X} * \mathrm{Y}$ females in the indicated prophase I stages. The data from all mice of each genotype are pooled in Fig. 2a. Littermates are indicated by underlined or circled numbers (b) Distribution of pachytene oocytes from $\mathrm{XX}, \mathrm{XX}^{*}$ and $\mathrm{X}^{*} \mathrm{Y}$ females in the classes P1, P2, P3 and P4. P1, 1-2 fully asynapsed chromosome arms; P2, one partially asynapsed arm; $\mathrm{P} 3$, full synapsis with strong extended $\gamma \mathrm{H} 2 \mathrm{AX}$ signal on 1-2 arms; $\mathrm{P} 4$, full synapsis with no strong $\gamma \mathrm{H} 2 \mathrm{AX}$ signal. The females $\mathrm{XX} \# 1$ and 2, $\mathrm{XX} * \# 2,3$ and 4, and $\mathrm{X}^{*} \mathrm{Y} \# 3$ are littermates, as well as the females $\mathrm{XX} * \# 1$ and $\mathrm{X}^{*} \mathrm{Y} \# 1$. Data from all mice of each genotype are pooled in Fig. 2b. (c) Centromere signal distribution on the quadrivalent in fully synapsed (P3 and $\mathrm{P} 4)$ pachytene oocytes from $\mathrm{XX}^{*}$ and $\mathrm{X}^{*} \mathrm{Y}$ females. The data from all mice of each genotype are pooled in Fig. 3g. 
Figure S2

a

Leptonema

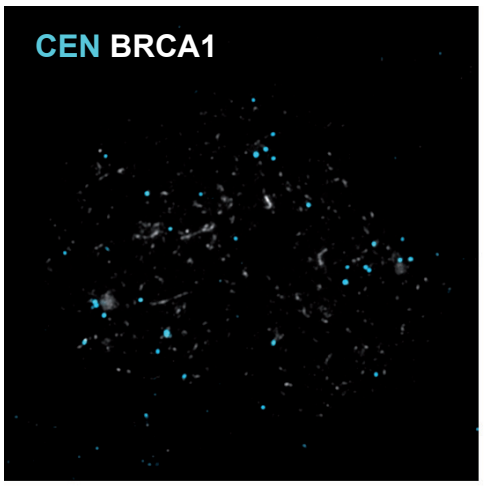

b

Zygonema

C

\section{Late \\ Zygonema}
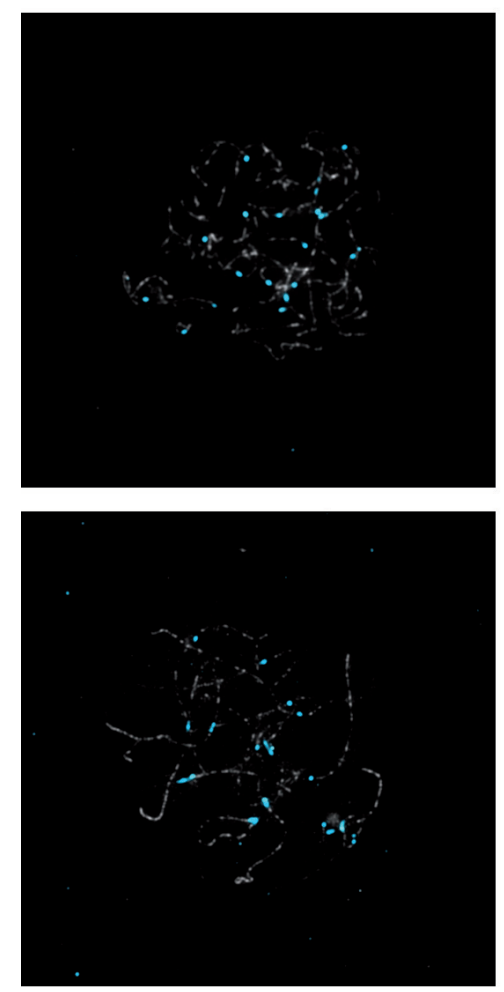

d

Pachynema

(P1)
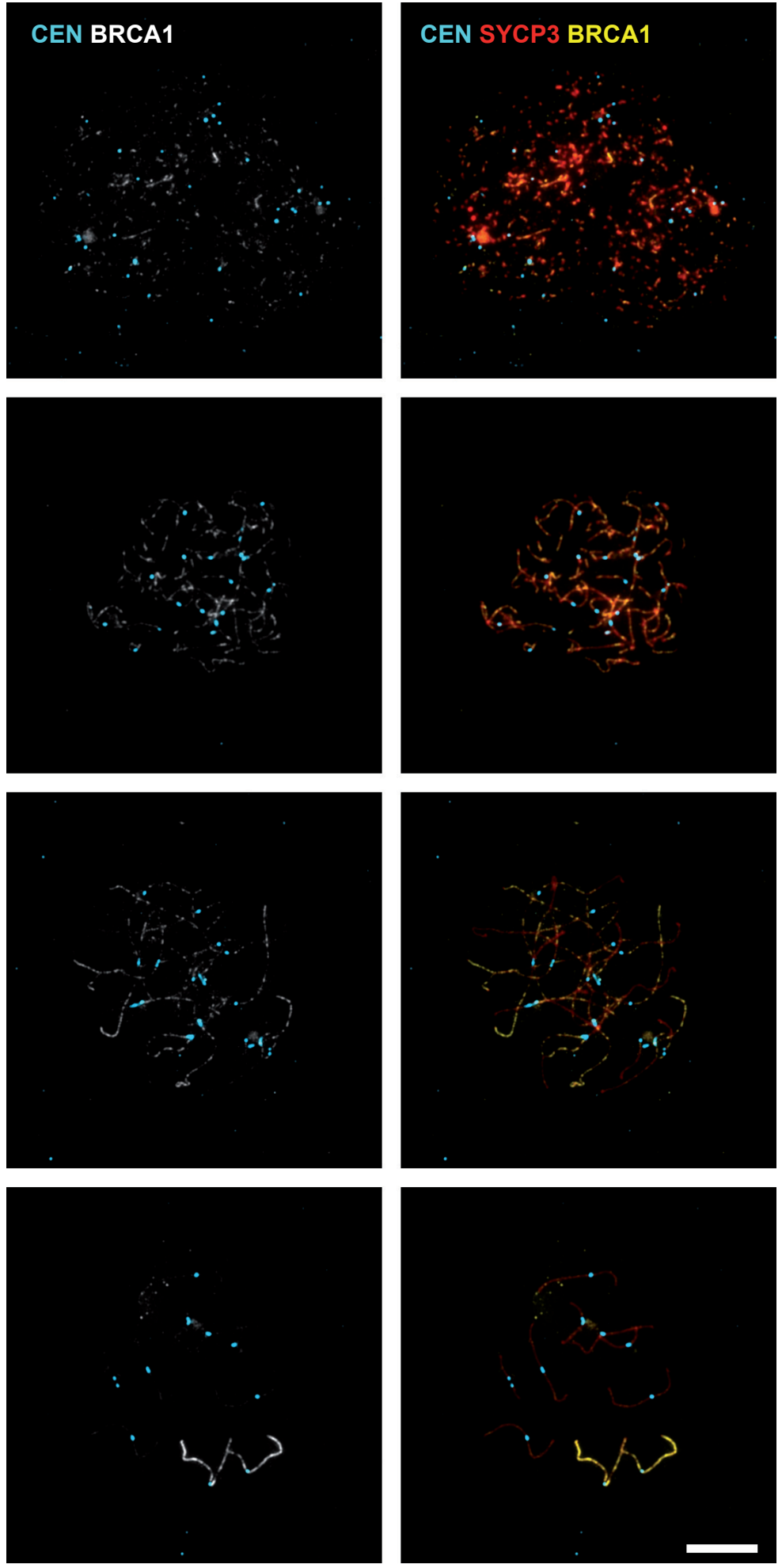
Figure S2. BRCA1 immunostaining during meiotic prophase progression in XX females. (a-d) Chromosome spreads of oocytes from XX females stained with antibodies against centromere proteins (CEN, CREST serum, light blue), a meiotic chromosome axis marker (SYCP3, red) and BRCA1 (white or green). Stages are indicated on the left. Scale bar $=10 \mu \mathrm{m}$. 
Figure S3
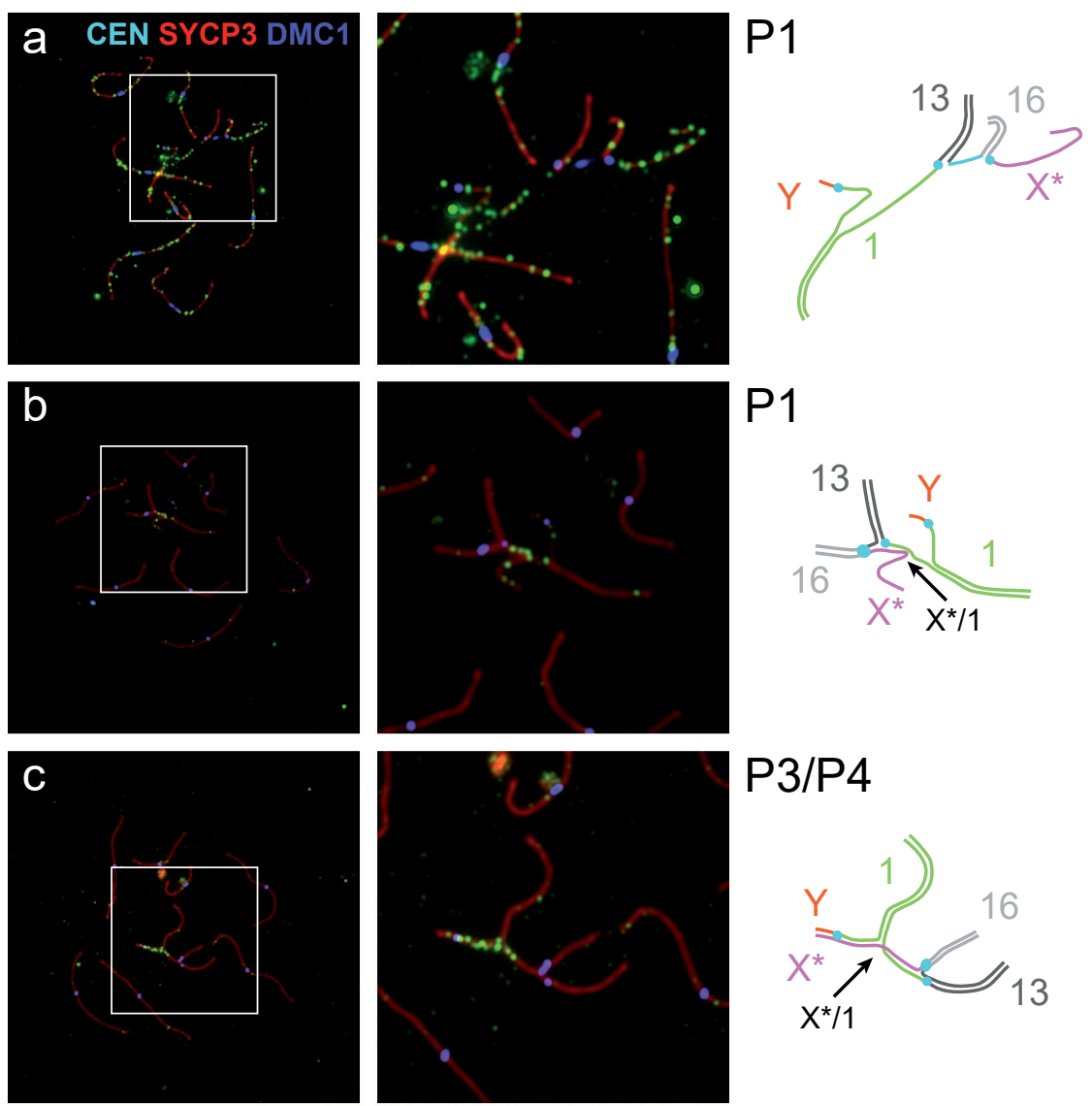

\section{P3/P4}
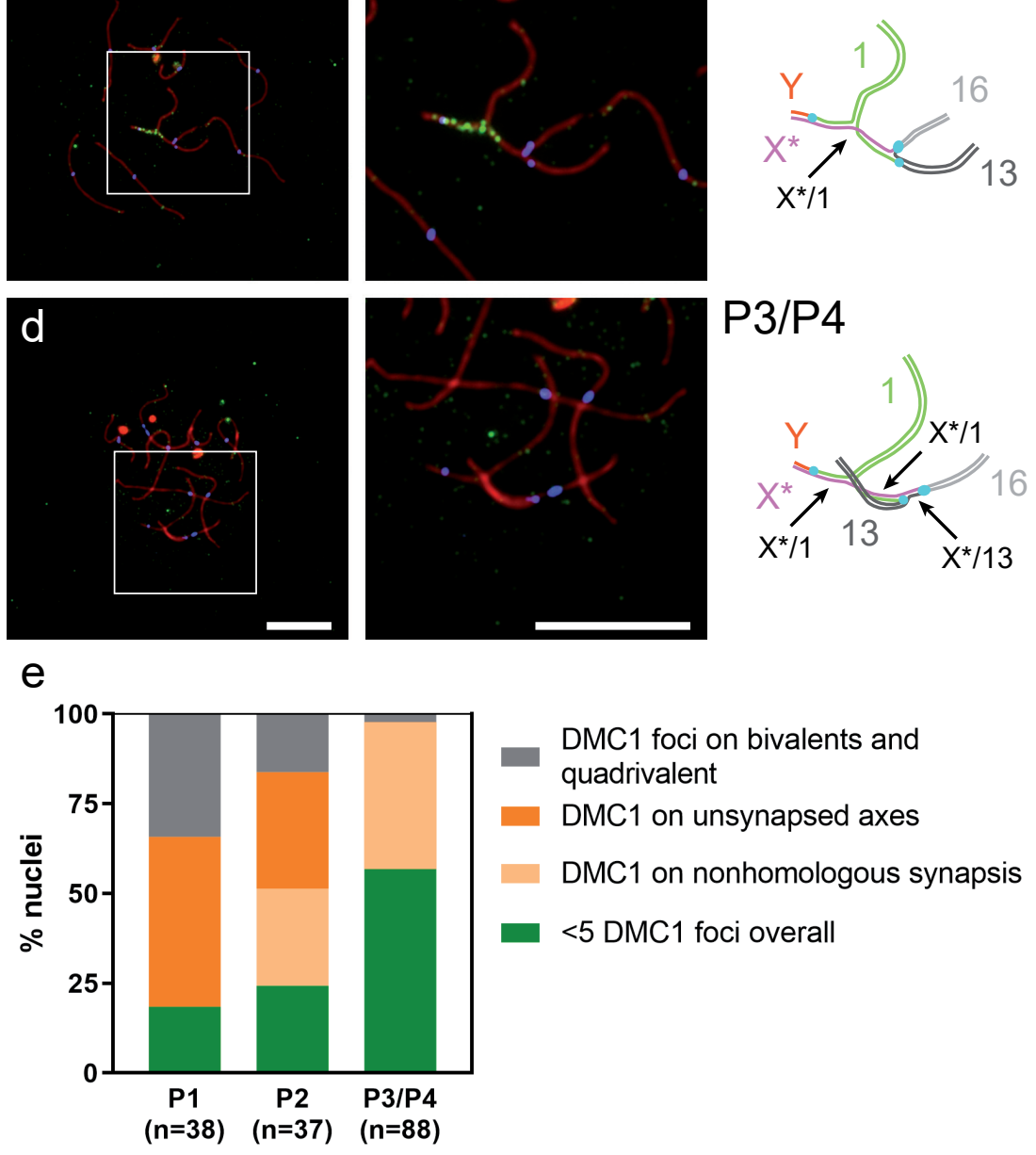
Figure S3. DMC1 immunostaining on meiotic chromosome spreads in one $X^{*} Y$ female. (a-d) Chromosome spreads of oocytes from one $\mathrm{X}^{*} \mathrm{Y}$ female $\left(\mathrm{X}^{*} \mathrm{Y}-1\right)$ were stained with antibodies against centromere proteins (CEN, CREST serum, blue), a meiotic chromosome axis marker (SYCP3, red) and DMC1 (green). P1, P3 and P4 classes as defined in the legend to Figure 2. Enlarged view from each nucleus shows the sex chromosome-containing quadrivalent, with the corresponding drawing on the right panel. Recognizable chromosome arms are indicated by colored arrowheads, with the same color code as in Fig. 1. Scale bars $=$ $10 \mu \mathrm{m}$. (e) Distribution of the nuclei with various patterns of DMC1 foci distribution among different classes of pachytene oocytes (P1, P2 and P3/P4). P3 and P4 nuclei were not distinguished due to the absence of $\gamma \mathrm{H} 2 \mathrm{AX}$ staining. P2 nuclei displaying DMC1 staining on both unsynapsed and nonhomologously synpased regions were categorized according to the prevailing staining. 
Figure S4

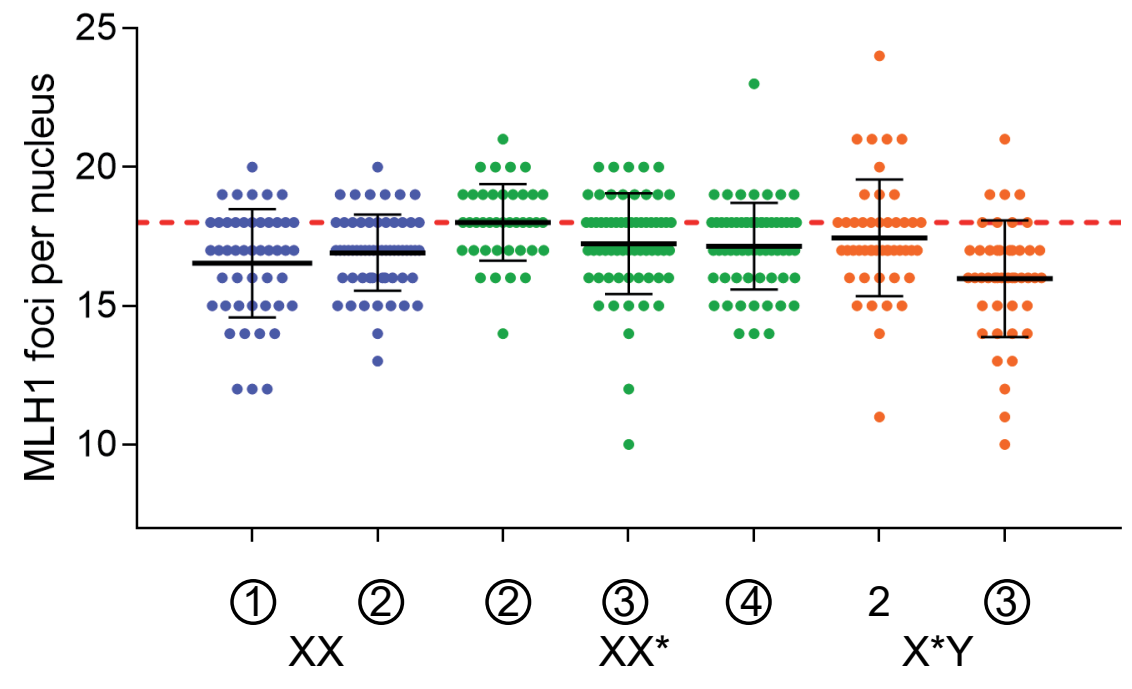


Figure S4. Numbers of MLH1 foci in XX, XX* and X*Y oocytes. (a) Number of MLH1 foci in pachytene nuclei displaying at least one MLH1 focus on each bivalent. Animals are the same as in Fig. S1, and the females XX \#1 and 2, $\mathrm{XX}^{*} \# 2,3$ and 4, and $\mathrm{X}^{*} \mathrm{Y} \# 3$ are littermates. The data from all mice of each genotype are pooled in Fig. 5e. Oocyte numbers: XX-1, n=47; XX$2, n=58 ; X^{*}-2, n=40 ; X X^{*}-3, n=63 ; X X^{*}-4, n=61 ; X^{*} Y-2, n=47 ; X^{*} Y-3, n=45$. 
Table S1. MLH1 foci in XX, $X^{*}$ and $X^{*} Y$ pachytene oocytes in each individual mouse

\begin{tabular}{|c|c|c|c|}
\hline & $\begin{array}{l}\text { MLH1 foci per } \\
\text { nucleus } \\
\text { (mean } \pm \text { SD) }\end{array}$ & $\begin{array}{l}\text { MLH1 foci per arm - } \\
\text { bivalents } \\
(\text { mean } \pm \text { SD) }\end{array}$ & $\begin{array}{l}\text { MLH1 foci per arm }- \\
\text { quadrivalent } \\
(\text { mean } \pm \text { SD) }\end{array}$ \\
\hline$X X-1$ & $16.5 \pm 1.9$ & $0.92 \pm 0.11$ & n. a. \\
\hline$X X-2$ & $16.9 \pm 1.4$ & $0.94 \pm 0.08$ & n. a. \\
\hline$X^{*}-2$ & $18.0 \pm 1.4$ & $1.00 \pm 0.08$ & $1.01 \pm 0.16$ \\
\hline $\mathrm{XX}^{*}-3$ & $17.2 \pm 1.8$ & $0.95 \pm 0.11$ & $0.99 \pm 0.17$ \\
\hline$X^{*}-4$ & $17.1 \pm 1.6$ & $0.96 \pm 0.09$ & $0.94 \pm 0.17$ \\
\hline$X^{*} \mathrm{Y}-2$ & $17.4 \pm 2.1$ & $0.96 \pm 0.12$ & $1.01 \pm 0.21$ \\
\hline$X^{*} Y-3$ & $16.0 \pm 2.1$ & $0.88 \pm 0.14$ & $0.88 \pm 0.20$ \\
\hline
\end{tabular}

